\title{
MÉXICO: EL ORGANISMO JUDICIAL (1950-1975)
}

\author{
Hector Fix-Zamudio
}

\section{Breve panorama de antecedentes}

1. Debemos hacer la aclaración previa de que, siguiendo el ejemplo de la Constitución de los Estados Unidos de 1787, la Constitución Federal de los Estados Unidos Mexicanos de 4 de octubre de 1824 estableció una dualidad de organismos judiciales: los tribunales de la Federación y los de los Estados, como en una época se implantó en Venezuela, ahora unificados ${ }^{1}$ y todavía subsiste en Argentina ${ }^{2}$ y Brasil ${ }^{3}$, de acuerdo con el régimen federal que se tomó del modelo estadounidense.

Este mismo sistema de doble jurisdicción se continuó en las Constituciones Federales de 5 de febrero de $1857^{4}$ y la vigente de 5 de febrero de $1917^{5}$, de manera que, tanto la Federación como las Entidades Federativas han organizado sus tribunales en la forma que han estimado más adecuada, aun cuando podemos observar que los de los Estados han seguido casi siempre el modelo del organismo judicial del Distrito Federal.

2. Por otra parte, también es preciso advertir que en la misma Carta Federal de 1824 se adoptó la denominación que todavía conservan los tribunales federales, de juzgados de Distrito, tribunales de Circuito y Suprema Corte de Justicia, que se tomó de manera evidente de la Ley Judicial Federal de los Estados Unidos de $1789^{6}$, pero como lo ha hecho notar la doctrina, especialmente los tratadistas Alfonso Noriega ${ }^{7}$ y Antonio Carrillo Flores ${ }^{8}$, en realidad tanto la estructura como las funciones de dichos tribunales, en particular de la Suprema Corte, se aproximaron más a los organismos judiciales de la Colonia, que a la de los Tribunales de los Estados Unidos.

En efecto, es evidente que la Suprema Corte de Justicia vino a sustituir a las Audiencias de México y Guadalajara existentes en la Nueva España, y aún al Consejo de Indias como órgano supremo de la justicia de las colonias españolas en América ${ }^{9}$ y que los demás tribunales federales sólo han funcionado como órganos auxiliares de este supremo tribunal.

1 Cfr. entre otros, Humberto J. La Roche, Instituciones Constitucionales del Estado Venezolano, Maracaibo, 5a. Ed., 1971, pp. 142-172.

2 Cfr. Joaquín V. González, Manual de la Constitución Argentina, Buenos Aires, Ed., 1971, pp. 569-628; Rafael Bielsa, Derecho constitucional, 3a. Ed., Buenos Aires, 1959, pp. 693-755, Germán J. Bidart Campos, Manual de Derecho Constitucional argentino, 4a. Ed., 1975, pp. 705-717.

3 Cfr. Pontes de Miranda, Comentários á Constituiçâo de 1946, 3a. Ed., Rio de Janeiro, 1960, tomo III, pp. 159-488; Luis Pinto Ferreira, Curso de direito constitucional, 3a. Ed., Sâo Paulo, 1974, $2^{\circ}$ Vol., p p. 362-409; Paulino Jacques, Curso de direito constitucional, p p. 227-249.

4 Cfr. entre otros, José M. del Castillo Velasco, Apuntamientos para el estudio del derecho constitucional mexicano, 3a. Ed., México, 1888; Mariano Coronado, Elementos de derecho constitucional mexicano, 3a. Ed., México, 1906, pp. 183-195; Eduardo Ruíz, Derecho constitucional, 2a. Ed., México, 1902, pp. 322-361.

5 Cfr. Felipe Tena Ramírez, Derecho constitucional mexicano, 12a. Ed., México, 1973, pp. $493-522$.

6 Sobre la citada ley orgánica del poder judicial federal de los Estados Unidos, cfr. Carl Brent Swisher, El desarrollo constitucional de los Estados Unidos, trad. Hugo Charny, Buenos Aires, 1958, tomo I, pp. $52-57$.

Cfr. El origen nacional y los antecedentes hispánicos del juicio de amparo, en “Jus”, México, septiembre de 1942, pp. 151-174.

8 Reflexiones del Sequicentenario, México, 1975, pp. 31-44. La Suprema Corte Mexicana como poder y como tribunal, en su libro "La Justicia Federal y la administración pública", 2a. Ed., México, 1973, pp. 299-354.

9 Cfr. Lucio Cabrera, El poder judicial federal mexicano y el Constituyente de 1917, México, 1968, pp. $12-24$. 
3. Lo anterior podemos corroborarlo, en cuanto las atribuciones que se otorgaron a la Suprema Corte de Justicia a partir de 1824 para conocer de las cuestiones relativas al equilibrio del régimen federal, inspiradas en la Carta de los Estados Unidos, no han funcionado en la práctica, como lo demuestra la inoperancia de las controversias señaladas en el artículo 105 de la Constitución Federal vigente ${ }^{\mathbf{1 0}}$, ni tampoco ha sido posible el funcionamiento de la Corte como órgano supremo de apelación federal, en los términos de los artículos 97 de la Carta de 1857 y 104 de la Ley Fundamental en vigor ${ }^{11}$, según lo han puesto de relieve los agudos estudios del tratadista Antonio Carrillo Flores' ${ }^{12}$.

4. Por el contrario, y en forma diversa de lo que ha ocurrido con la competencia de la Corte Suprema Argentina y del Tribunal Supremo Federal del Brasil, a través del recurso extraordinario constitucional, que inspirándose en el sistema estadounidense, presupone la existencia de un "caso federal" para poder impugnar las resoluciones de los tribunales locales ante el órgano máximo de la justicia federal; a partir de 186913 en nuestro país se inició una creciente centralización de la justicia local a través del reconocimiento del juicio de amparo contra las sentencias de todos los tribunales del país, debido a una interpretación forzada del artículo 14 de la Constitución de 1857, como lo puso en evidencia el profundo pensamiento de Emilio Rabasa ${ }^{14}$.

En consecuencia, a partir de entonces, con la plena y expresa aceptación del Constituyente de Querétaro de 1916-1917, se reconoció la necesidad de conservar dicha centralización ${ }^{15}$, consagrándose en los artículos 14, 16 y 107 de nuestra Carta Fundamental vigente, la procedencia del juicio de amparo contra las sentencias de todos los tribunales del país, con lo cual la Suprema Corte de Justicia consolidó su carácter de tribunal supremo de casación, y sólo en proporción muy reducida, de órgano de justicia constitucional, y si bien ese porcentaje ha pretendido reducirse en las reformas constitucionales y legales que se han promulgado en los años de 1950 y 1967, el peso tremendo del control de la legalidad, particularmente en cuanto a la impugnación de las sentencias judiciales, ha impedido un desarrollo similar al de la Corte Federal de los Estados Unidos, ya que esta última se aproxima cada vez más a las características de un verdadero tribunal constitucional ${ }^{16}$.

5. El mismo Emilio Rabasa, quien señaló la evolución de la Suprema Corte hacia un tribunal de casación, manifestó en los primeros años de este siglo, que la acumulación de amparos en materia judicial en el citado Alto Tribunal transformaban su función en imposible ${ }^{17}$, y este problema del rezago de los tribunales

10 Cfr. Manuel Herrera y Lasso, Estudios Constitucionales. Segunda serie, México, 1964, pp. $260-271$.

11 Cfr. Lucio Cabrera, El poder judicial federal mexicano, cit., p p. 130-145.

12 Reflexiones del Sesquicentenario, cit., pp. 47-105; La Suprema Corte como poder o como tribunal, cit., pp. 299-354.

13 El primer asunto en el cual la Suprema Corte declaró implícitamente la inconstitucionalidad del artículo $8^{\circ}$ de la Ley de Amparo de 1869, que prohibió expresamente la procedencia del amparo contra sentencias judiciales, fue la sentencia dictada el 20 de julio de ese propio año de 1869 , en el juicio de amparo promovido por Miguel Vega, y que provocó un serio razonamiento con el Congreso Federal, cfr. Antonio Carrillo Flores, Reflexiones del Sesquicentenario, cit., pp. 42-44.

14 El artículo 14. Estudio Constitucional, 2a. Ed., conjuntamente con la obra del mismo autor ${ }^{\alpha}$ El Juicio Constitucional", México, 1955, pp. 3-128.

15 Deben recordarse las siguientes frases de la exposición de motivos del proyecto de Constitución presentado por don Venustiano Garranza a los Constituyentes de Querétaro el primero de diciembre de 1916: "El pueblo mexicano está ya tan acostumbrado al amparo en los juicios civiles, para librarse de las 1916: "El pueblo mexicano está ya tan acostumbrado al amparo en los juicios civiles, para librarse de las impolítico, privarlo ahora de tal recurso estimando que bastará limitarlo únicamente a los casos de verdadera y positiva necesidad, dándole un procedimiento fácil y expedito para que sea efectivo, como se servirá ver la Cámara en las bases que se proponen para su reglamentación ..."

16 Cfr. Paul G. Kauper, The Supreme Court: Hybrid Organ of State, en "Southwestern Law Journal", Dallas, Texas, otoño de 1967, pp. 573-590.

17 El capítulo XIII de su libro ya mencionado, El artículo 14, pp. 103-110, lo intitula precisamente "La imposible tarea de la Corte". 
federales, pero particularmente del más Alto Tribunal de la República, ha constituído la pesadilla permanente de los gobiernos posteriores a la revolución de 1910, y la mayor parte de las reformas constitucionales sobre el organismo judicial federal están orientadas de manera esencial para resolver esta situación ${ }^{18}$, olvidándose en forma inconsciente o intencionada de otros aspectos que a nuestro modo de ver son indispensables para restituir al organismo judicial federal en su verdadera jerarquía, e inclusive dar mayor vigor a los tribunales locales.

6. Finalmente también es preciso señalar que si bien el organismo judicial federal ha desempeñado un papel bastante decoroso, y en algunas ocasiones valiente, frente a los otros dos organismos del poder - y esto que un autor de la jerarquía de Rabasa le negaba el carácter de verdadero poder ${ }^{19}$ - no se le ha permitido desarrollar en forma vigorosa su función de máximo intérprete y guardián de la Constitución Federal, como lo demuestra el hecho evidente, de preferir se el sistema poco recomendable de la reforma de los textos fundamentales, sobre el más espontáneo y natural de la evolución constitucional mediante la interpretación judicial ${ }^{20}$, y esto también ha repercutido en los estudios jurídicos, si tomamos en cuenta que sólo se han elaborado dos estudios generales sobre el organismo judicial, el primero redactado por el distinguido tratadista Jacinto Pallares en 187421, y sólo en época reciente el certero análisis del poder judicial federal del profesor Lucio Cabrera ${ }^{22}$.

Por otra parte, existen ecasos trabajos sobre la Suprema Corte de Justicia, con excepción de los elaborados por Antonio Carrillo Flores ${ }^{23}$; no ha llegado a nuestro conocimiento ninguno respecto a los tribunales de las Entidades Federativas, y para completar este cuadro desalentador, tampoco son abundantes los estudios sistemáticos sobre la jurisprudencia ${ }^{24}$, en contraposición a lo que ocurre respecto de esta última en algunos países latinoamericanos, especialmente en Argentina ${ }^{25}$.

\section{Las reformas constitucionales a la justicia federal promulgadas en 1950 y 1967}

\section{A Las reformas de 1950}

Para entender los propósitos de las citadas reformas, es preciso tomar en cuenta la situación de los tribunales federales en los años anteriores a las mismas, y los diversos intentos que se hicieron para aliviar el peso tremendo que agobiaba

18 Cfr. Héctor Fix-Zamudio, Reformas constitucionales al poder judicial federal, en "Revista de la Facultad de Derecho de México", Núm. 65, enero-marzo de 1967, pp. 83-123.

19 De acuerdo con este ilustre jurisconsulto, a la función judicial le faltan las condiciones esenciales de los órganos del poder, es decir, iniciativa, unidad y autoridad general, La Constitución y la dictadura, 3a. Ed., México, 1956, pp. 189-190.

$20 \mathrm{Cfr}$. Jorge Carpizo y Héctor Fix-Zamudio, Algunas reflexiones sobre la interpretación constitucional en el ordenamiento mexicano, en el volumen colectivo, "La interpretación constitucional", México, 1975, pp. $9-58$.

21 El Poder Judicial, México, 1874.

22 El poder judicial federal mexicano y el Constituyente de 1917, México, 1968.

23 Especialmente sus trabajos ya citados, La Suprema Corte Mexicana como poder y como tribunal, y Reflexiones del Sesquicentenario, pero además, La Suprema Corte en las reformas sociales de México, en "Revista de la Facultad de Derecho de México", Núm. 55, julio-septiembre de 1964, pp. 639-645.

24 Contrariamente a lo que ocurre en los países angloamericanos, los repertorios de jurisprudencia son escasos en nuestro país, y sólo recientemente se ha iniciado la publicación de tesis jurisprudenciales más actualizadas, como las contenidas en la "Gaceta Informativa de Legislación y Jurisprudencia", trimestral a partir de 1972, y el "Boletín del Semanario Judicial de la Federación", mensual, 1974.

25 Como un ejemplo podemos citar la existencia de dos periódicos diarios que publican tesis y comentarios jurisprudenciales, como "La Ley" y "Jurisprudencia Argentina". 
especialmente a la Suprema Corte de Justicia, debido al rezago de los amparos contra sentencias judiciales que se habían acumulado en número creciente y progresivo, los que no podían resolverse a través de la estructura de los tribunales federales, entonces vigente.

8. En efecto, después de las reformas constitucionales de 1928 y 1934, la primera que había dividido el funcionamiento de la Suprema Corte en tres salas según la materia, para conocer de los juicios de amparo que con anterioridad se decidían por el Tribunal en pleno ${ }^{26}$, y la segunda que estableció una Cuarta Sala especializada en materia laboral27, se pudo observar que estas soluciones a través de las cuales se esperaba resolver el problema del rezago como enfermedad crónica de la justicia federal, no impidieron que se acumularan nuevamente, también en la Suprema Corte, los juicios de amparo pendientes de resolución, tomando en cuenta esa tarea imposible que señaló Emilio Rabasa desde principios de nuestro Siglo, de decidir las controversias relativas a todo el ordenamiento jurídico del país.

9. Con el propósito fundamental de aliviar el rezago, se elaboraron varios proyectos de reforma constitucional los años de 1944 y 1945.

a) El proyecto de reformas al artículo 107 constitucional presentado al Congreso de la Unión por el Presidente de la República General Manuel Avila Camacho, el 21 de diciembre de 1944, fue aprobado rápidamente por ambas Cámaras, pero no se sometió a las legislaturas de las Entidades Federativas, debido a la oposición de la Suprema Corte de Justicia, que se manifestó contraria a las citadas reformas ${ }^{28}$.

La principal innovación del citado proyecto fue depositar en el propio Congreso de la Unión la facultad de establecer la competencia de los diversos tribunales federales, señalando privativamente la de la Suprema Corte de Justicia, de manera similar al criterio seguido en la Constitución Federal de los Estados Unidos, que en su artículo tercero señala la competencia de la Corte Suprema Federal, pero confiere al órgano legislativo de la Unión la facultad de fijar, a través de ordenamiento secundario, la de los restantes tribunales de la Federación ${ }^{29}$.

En el propio proyecto de reformas se proponía como competencia de la Suprema Corte de Justicia, el conocimiento de los juicios de amparo en los que se impugnara la inconstitucionalidad de una ley federal o local, cuando se reclamara la violación directa de un precepto constitucional; tratándose de actos contrarios a la jurisprudencia de los tribunales federales, o los que afectaran gravemente el interés público.

10. La principal objeción que se hizo al citado proyecto de 1944 , fue dejar al Congreso de la Unión la determinación de la competencia de los tribunales federales, que entonces y ahora está señalada en el texto del artículo 107 constitucional; y por otra parte, se estimó indebida la distinción entre violaciones

26 El texto primitivo del artículo 94 de la Constitución Federal, en su parte conducente establecía: a ... La Suprema Corte de Justicia de la Nación se compondrá de once ministros y funcionará siempre en tribunal pleno, siendo sus audiencias públicas, excepción de los casos en que la moral o el interés público así lo exigiere, debiendo celebrar sus sesiones en los periódos y términos que establezca la ley....

27 El invocado artículo 94 de la Constitución Federal, de acuerdo con la reforma de 1934, dispuso en su parte relativa: “. . L La Suprema Corte de Justicia de la Nación se compondrá de veintiún ministros y funcionará en Tribunal Pleno o dividida en cuatro Salas de cinco ministros cada una, en los términos

28 Cfr. el folleto publicado por la Suprema Corte de Justicia, El problema del rezago de juicios de amparo en materia civil, México, 1946, pp. 63-78.

29 Cfr. entre otros, Bernard Schwartz, Los poderes del gobierno. Comentario sobre la Constitución de los Estados Unidos, trad. de Juan José Olloqui Labastida, tomo I, "Poderes federales y estatales", México, 1966, pp. 419-445; Lewis Meyers, El sistema legal norteamericano, trad. de Atanasio Sánchez, 2a. Ed., Buenos Aires, 1969, pp. 11-16. 
constitucionales directas y las de las disposiciones legales secundarias, que se han considerado por un sector de la doctrina y de la jurisprudencia como inseparables, apoyándose en lo dispuesto por los artículos 14 y 16 de la misma Carta Federal, de acuerdo con los cuales, toda violación a una disposición legal, de cualquier naturaleza, adquiere automáticamente el carácter de infracción constitucional ${ }^{30}$.

b) Como una contrapropuesta a la iniciativa presidencial mencionada anteriormente, el Tribunal en Pleno de la Suprema Corte de Justicia elaboró, a su vez, un diverso anteproyecto que aprobó el 17 de julio de 1945, que conservaba la competencia de los tribunales federales a través de reglas expresas establecidas en el texto constitucional, pero proponía que se encomendara a los tribunales de circuito (entonces los tribunales unitarios existentes desde 1824 como órganos de apelación de los procesos ordinarios federales), el conocimiento de la segunda instancia de los juicios de amparo en materia civil contra resoluciones judiciales que no fuesen sentencias definitivas, estas últimas impugnables en amparo de una sola instancia, que debería encomendarse, como hasta entonces, a las Salas de la misma Suprema Corte.

También se propuso el establecimiento de la institución denominada "sobreseimiento por inactividad procesal" precisamente en los juicios de amparo contra resoluciones judiciales en materia civil, configurando una carga procesal de impulsión a las partes que deberían demostrar su interés en la prosecusión y resolución de estas controversias.

La razón fundamental de las propuestas de la Suprema Corte se debía al considerable rezago que padecía entonces la Tercera Sala de la propia Suprema Corte, y con estos dos procedimientos se pretendía desahogar al máximo Tribunal de la República de ese enorme peso ${ }^{31}$.

c) 11. Fue durante el gobierno del Presidente Miguel Alemán, cuando, con apoyo en el citado anteproyecto de la Suprema Corte de 1945, se elaboró una iniciativa que fue aprobada por ambas Cámaras del Congreso de la Unión y por la mayoría de las legislaturas de las Entidades Federativas, en los términos del artículo 135 de la Constitución Federal, y que modificó tanto disposiciones de la misma Carta Fundamental, como de la Ley de Amparo y de la Ley Orgánica del Poder Judicial Federal, significando una verdadera restructuración orgánica y procesal de los tribunales federales en lo relativo a su connocimiento del juicio de amparo, y que algunos tratadistas calificaron como "Reforma Alemán"32.

Esta reforma ha sido una de las fundamentales del organismo judicial federal con posterioridad a la Constitución de 1917, pero siempre orientada a aliviar a la Suprema Corte de Justicia del rezago que periódicamente la agobia.

12. Sería difícil en unas cuantas líneas señalar, así sea superficialmente, las diversas modificaciones que implicó para los tribunales federales la citada reforma constitucional y legal de 1950, que entró en vigor en el mes de mayo de 1951, pero podemos señalar que la más importante fue el establecimiento de nuevos órganos de la justicia federal, al lado de los tradicionales tribunales unitarios de circuito, que subsistieron como órganos de apelación en materia ordinaria

30 Cfr. el citado folleto, El problema del rezago de juicios de amparo en materia civil, pp. 69-77. Carlos Arellano García, El rezago en el amparo, México, 1966, pp. 86-87.

$31 \mathrm{Cfr}$. el mismo folleto citado en la nota anterior, pp. 79-106. Carlos Arellano García, op.ult.cit., pp. 87-93; Ignacio Burgoa, El juicio de amparo, cit., pp. 910-911.

32 Así la denominó expresamente Romeo León Orantes, El juicio de amparo, 3a. Ed., Puebla, 1956, pp. $90-138$. 
federal, es decir, nos referimos a los tribunales colegiados de circuito en materia de amparo, integrados por tres magistrados, con la función específica de auxiliar a la Suprema Corte de Justicia en el conocimiento de los juicios de amparo tanto de una sola instancia como de doble grado, en aquellos aspectos que se consideraron de menor importancia.

También se aumentó el número de los magistrados de la Suprema Corte con cinco supernumerarios, con la doble función de sustituir a los numerarios e integrar una Sala Auxiliar con la competencia que le encomendara el Tribunal en Pleno.

La creación de los tribunales colegiados de circuito se inspiró, aun cuando no se dijera expresamente, en la reforma a la organización judicial de los tribunales federales de los Estados Unidos en el año de 1891, cuando se establecieron tribunales de circuito de apelación precisamente para aliviar a la Corte Suprema Federal del gran número de asuntos que impedían su debido funcionamiento ${ }^{33}$.

13. La división de la competencia entre los tribunales colegiados de circuito y la Suprema Corte de Justicia fue bastante complicada, pero en el aspecto esencial del rezago, se dividió el conocimiento del juicio de amparo contra sentencias judiciales, correspondiendo la resolución de las violaciones procesales a los citados tribunales colegiados, y la resolución de las violaciones de fondo a las Salas respectivas de la Suprema Corte; y en cuanto a los amparos de doble instancia, de los cuales el número más importante eran los enderezados contra actos de autoridades administrativas, se encomendó a la Sala respectiva de la Corte el conocimiento de la segunda instancia de los juicios de amparo formulados contra autoridades administrativas federales -agregando la jurisprudencia en esta categorí a las autoridades administrativas del Distrito Federal ${ }^{34}$-, y los restantes se enviaron a los citados Tribunales Colegiados ${ }^{35}$.

Otro aspecto importante inspirado en el anteproyecto de 1945, fue la introducción definitiva - con varios antecedentes de carácter transitorio ${ }^{36}$ - del sobreseimiento por inactividad procesal, es decir la carga de impulsión para el promovente de asuntos civiles y administrativos, excluyéndose la reclamación de la inconstitucionalidad de una ley, en un plazo de ciento ochenta días consecutivos que la jurisprudencia consideró como hábiles, a partir de la última actuación procesal, y en el supuesto de no cumplir con esa carga debía sobreseerse el juicio respectivo; institución muy discutida desde entonces por la doctrina ${ }^{37}$.

14. En los primeros años de aplicación de estas reformas se produjo un alivio relativo en el rezago de los asuntos encomendados a la Suprema Corte de Justicia, si se toma en cuenta que al establecerse los primeros cinco tribunales colegiados de circuito en diversas regiones del país, la propia Suprema Corte se descargó nada

33 Sobre la creación de los Tribunales de Circuito de Apelación, cfr. Carl Brent Swisher, El desarrollo constitucional de los Estados Unidos, cit., tomo I, pp. 437-438.

34 Este criterio de la Segunda Sala de la Suprema Corte contribuyó a aumentar el rezago de la propia Sala y por ello en la exposición de motivos de la iniciativa presidencial enviada a la Cámara de Senadores en noviembre de 1965, para justificar la proposición de encomendar esta materia a los Tribunales Colegiados de Circuito, se sostuvo “... Con esta medida se descarga a la segunda sala de los numerosos amparos en revisión en que aparecen, como responsables las autoridades del Departamento del Distrito Federal, los cuales por referirse a una circunstancia territorial determinada, no hay razón para que se lleven ante la Suprema Corte, sino que su conocimiento debe corresponder a los Tribunales Colegiados de Circuito, al igual de lo que acontece actualmente con las revisiones en los amparos en que las autoridades responsables pertenecen a la esfera local ...."

35 Cfr. Romeo León Orantes, El juicio de amparo, cit., pp. 129-131.

$36 \mathrm{Cfr}$. Alfredo Borboa Reyes, El sobreseimiento en el juicio de amparo por inactividad procesal, México, 1957, pp. $55-70$.

37 Cfr. Ignacio Burgoa, El juicio de amparo, cit., pp. 471-476. 
menos que de veintisiete mil juicios de amparo que se enviaron a los referidos referidos tribunales colegiados, pero pronto se advirtió que las citadas reformas, si bien resultaban benéficas, eran insuficientes y además se les señalaron varios defectos importantes:

En primer término no resultaba afortunada la división entre violaciones procesales y de fondo para establecer la competencia del conocimiento de los juicios de amparo de una sola instancia contra sentencias definitivas de carácter judicial, ya que sólo complicaba la tramitación de los propios juicios y provocaba serios problemas competenciales; en segundo lugar, por un error del legislador secundario no se estableció la jurisprudencia obligatoria de los fallos de los nuevos tribunales colegiados, ni tampoco se introdujo un eficaz sistema de unificación de sus criterios, a los cuales no se les daba debida publicidad, lo que provocó críticas por la inseguridad jurídica que provocaba la diversidad de tesis jurídicas sobre los mismos problemas ${ }^{38}$; y finalmente, también por falta de cuidado en la legislación reglamentaria del amparo, la inactividad procesal recayó siempre sobre el promovente del amparo, aun cuando se tratara de la segunda instancia y hubiese obtenido sentencia favorable en la primera, defecto de técnica que producía graves injusticias y que fue objeto de constantes críticas ${ }^{39}$.

15. Diez años después, es decir en el año de 1960, la Suprema Corte ya tenía un rezago de más de ocho mil asuntos, en su gran mayoría juicios de amparo, de los cuales cinco mil se encontraban en la Sala Administrativa (Segunda), por lo que el problema radicaba ya entonces en el constante crecimiento de los juicios de amparo contra actos de autoridades administrativas ${ }^{40}$.

Por otra parte, por reforma de diciembre de 1957, que entró en vigor el primero de enero de 1958, se modificó la Ley Orgánica del Poder Judicial de la Federación, atribuyendo competencia al Tribunal en Pleno de la Suprema Corte de Justicia para conocer de la segunda instancia de los juicios de amparo interpuestos contra la inconstitucionalidad de una ley, que anteriormente correspondía a las Salas de la misma Corte según su materia, por considerar el legislador que la decisión final sobre la constitucionalidad de las disposiciones legales debe corresponder al órgano máximo de la justicia federal ${ }^{41}$ lo que provocaría en algunos años un rezago también en el propio Pleno, en relación con esta materia.

16. En poco tiempo renació la inquietud sobre el recargo de labores de la Suprema Corte de Justicia, particularmente, como ha ocurrido siempre, en relación con el conocimiento de los juicios de amparo, y por tal motivo se propusieron nuevas reformas, entre las cuales podemos señalar la iniciativa presentada al Congreso de la Unión por el senador Rodolfo Brena Torres de septiembre de $1959^{42}$ y los anteproyectos personales elaborados en 1958 y 1965 por el distinguido profesor Ignacio Burgoa.

El proyecto del Senador Brena Torres volvió a resucitar, hasta cierto punto, la idea de la iniciativa presidencial de 1944 , en cuanto a la división de la competencia

38 Cfr. Héctor Fix-Zamudio, Algunas consideraciones respecto a las reformas constitucionales al poder judicial federal, en "Boletín del Instituto de Derecho Comparado de México", Núm. 55, enero-abril de 1966, pp. 60-63.

39 Cfr. Alfredo Borboa Reyes, El sobreseimiento en el juicio de amparo, cit., pp. 166-177; Ignacio Burgoa, El juicio de amparo, cit. pp. $475-476$.

40 Véase la parte del Informe de la Suprema Corte de Justicia correspondiente al año de 1960, relativa al informe del licenciado Rafael Matos Escobedo, Presidente de la Segunda Sala, pp. 3-11.

41 Cfr. Antonio Carrillo Flores, Reflexiones del Sesquicentenario, cit., pp. 79-80.

42 Cfr. Héctor Fix-Zamudio, Algunas consideraciones respecto a las reformas constitucionales, cit., pp. 31-33; Carlos Arellano García, El rezago en el amparo, cit., pp. 99-102. 
entre la Suprema Corte y los restantes tribunales federales, de acuerdo con la naturaleza constitucional o legal de las violaciones alegadas en el juicio de amparo, de manera que a la Suprema Corte integrada únicamente por once magistrados -en contraste con los 21 numerarios y 5 supernumerarios que entonces y ahora integran la propia Corte- conocería fundamentalmente de los juicios de amparo interpuestos contra la inconstitucionalidad de las leyes, desplazando todos los restantes juicios de amparo en los cuales se discutiese la legalidad de los actos de autoridad, hacia los tribunales colegiados de circuito $^{43}$.

En cuanto a las proposiciones de reforma del profesor Burgoa, en esencia pueden resumirse en la supresión de los tribunales colegiados de circuito y el aumento de las Salas de la Suprema Corte de Justicia en el número necesario para atender los asuntos que aumentaban el rezago de la propia Corte y los citados tribunales; Salas que primero propuso se concentraran en esta ciudad de México, y en el segundo proyecto, debían distribuirse en toda la República, con una Sala Central en esta ciudad, para la unificación de la jurisprudencia ${ }^{44}$.

\section{B. Reformas promulgadas en 1967}

17. A pesar del auxilio de los citados tribunales colegiados de circuito, se presentó nuevamente en la Suprema Corte de Justicia la vieja enfermedad del rezago que ya señalaba Emilio Rabasa en los primeros años este siglo, de manera que el Pleno de la Suprema Corte de Justicia elaboró un nuevo anteproyecto en el año de 1965, que sin modificación alguna hizo suyo el Presidente Gustavo Díaz Ordaz y lo envió al Senado de la República como Cámara de origen, en el mes de noviembre del citado año de $1965^{45}$.

Lo anterior se explica claramente, si tomamos en cuenta que para el citado año de 1965 la Suprema Corte de Justicia terminó su ejercicio con un rezago de dieciséis mil asuntos, como siempre en su mayor parte juicios de amparo, de los cuales más de tres mil correspondían al Tribunal en Pleno y seis mil a la Sala Administrativa del propio Alto Tribunal ${ }^{46}$.

18. En consecuencia, la preocupación principal de la Suprema Corte al elaborar el citado anteproyecto, y posteriormente al ser aprobado con ligeras modificaciones por el Congreso de la Unión, también por parte del legislador, radicó como periódicamente ha ocurrido, en aliviar el rezago de la propia Corte, intentando una nueva distribución de competencias, de tal manera que se enviaran mayor número de asuntos a los tribunales colegiados de circuito.

No existió entonces tampoco la intención de realizar una reforma a fondo de la estructura y el funcionamiento del organismo judicial federal, sino exclusivamente corregir los errores técnicos en que habían incurrido las reformas de 1950, centrando su preocupación en un nuevo reparto de competencias entre la Suprema Corte de Justicia y los tribunales colegiados de circuito, exclusivamente en relación con los juicios de amparo.

43 Cfr. Ignacio Burgoa, El juicio de amparo, cit., pp. 809-814.

44 Cfr. Ignacio Burgoa, Reformas a la ordenación positiva vigente del amparo, Meéxico, 1958; Proyecto de reformas al Poder Judicial de la Federación, México, 1965; El juicio de amparo, cit., pp. 918-932.

45 El texto íntegro de la citada iniciativa, incluyendo una amplia exposición de motivos, fue publicado en los periódicos de mayor circulación, el lunes 29 de noviembre de 1965.

46 Véase el Informe de labores de la Suprema Corte de Justicia, correspondiente al año de 1965. 
19. Estas reformas constitucionales y legales fueron publicadas los días 25 de octubre de 1967 y 30 de abril de 1968, y entraron en vigor el 18 de octubre del citado año de 1968.

Los aspectos más importantes de las modificaciones mencionadas pueden enunciarse como sigue:

a) Se cambia el criterio de distribución de las competencias para conocer del juicio de amparo ante la Suprema Corte de Justicia y los tribunales colegiados de circuito, de manera que ya no se apoya en el género de violaciones procesales y de fondo tratándose del amparo contra sentencias judiciales, sino que se toman en cuenta respecto de los diversos tipos de amparo, criterios patrimoniales o de carácter social, para establecer la citada distribución, de manera que se reservan a la Suprema Corte los de mayor trascendencia, como los relativos a la inconstitucionalidad de las leyes; los asuntos civiles de más de cien mil pesos de cuantía; los administrativos contra autoridades o tribunales federales por más de quinientos mil pesos (a no ser que la misma Corte estime que existe interés nacional); los asuntos de familia y del estado civil; los intentados contra las sentencias de los tribunales federales del trabajo y los de carácter penal, y en los casos de impugnación de resoluciones de tribunales locales, tratándose de conflictos colectivos laborales; los relativos a los derechos colectivos agrarios o de la pequeña propiedad; o cuando la pena aplicada al procesado excede de cinco años de prisión, etc. ${ }^{47}$.

Este criterio de distribución hizo renacer la polémica sobre si es posible dividir y clasificar las violaciones legales y constitucionales, tomando en cuenta aspectos patrimoniales y de carácter social, ya que se ha sostenido, que todas las infracciones a cualquier norma legal, de la naturaleza o jerarquía que sean, deben considerarse de carácter constitucional por virtud de los artículos 14 y 16 de la Constitución Federal, y por ello volvió a insistirse por algunos juristas sobre la necesidad de que la última instancia de todos los asuntos judiciales llegase, a través del amparo, hasta la Suprema Corte de Justicia, ya que no podían concebirse violaciones constitucionales de primera y segunda categoría ${ }^{48}$.

b) En segundo lugar, tomando en cuenta también el rezago que agobiaba al Tribunal en Pleno de la Suprema Corte, en cuanto al conocimiento de la segunda instancia de los juicios de amparo intentados contra la inconstitucionalidad de una ley, se adopta el sistema de que una vez establecida la jurisprudencia obligatoria por el mismo Tribunal en Pleno sobre esta materia ${ }^{49}$, los asuntos similares deben turnarse a las Salas de la propia Corte, según su materia, a fin de que apliquen dicha jurisprudencia, sin perjuicio de que la Sala respectiva pueda estimar que deba revisarse esa jurisprudencia en un asunto determinado, que debe regresar al Pleno para que decida lo conducente (artículos 107, fracción VIII, de la Constitución Federal, y 84, fracción I, inciso a), de la Ley de Amparo).

47 Cfr. Héctor Fix-Zamudio, Algunas consideraciones respecto a las reformas constitucionales, cit., pp. 37-44; Carlos Arellano García, El rezago en el amparo, cit., pp. 132-149.

48 Este último punto de vista fue expresado por el distinguido jurista mexicano Alfonso Noriega Cantú, en su agudo comentario publicado en el periódico "Excelsior" de 23 de diciembre de 1965, p. 7-A., con el título Respeto a la Constitución. El proyecto de reformas al amparo. En el mismo sentido se pronunció el magistrado Alfonso Trueba en su cuidadoso artículo intitulado Todavía es proyecto. Mejoramiento de la Justicia, también aparecido en el periódico "Excelsior" de 3 de febrero de 1966, pp. 7-8-A, en cuya parte conducente, este último tratadista sostuvo que: "La violación de garantías pp. 7-8-A, en cuya parte conducente, este último tratadista sostuvo que: "La violación de garantías
individuales tiene en todos los casos la misma naturaleza intrínseca y, por lo mismo, no puede admitirse que hay violaciones de derechos constitucionales que valen o tienen una cuantía mayor o menor que otras".

49 Reçuérdese que, de acuerdo con el artículo 192 de la Ley de Amparo, el Tribunal en Pleno establece jurisprudencia obligatoria cuando sustenta el mismo criterio en cinco resoluciones no interrumpidas, pronunciadas en el mismo sentido y por el voto aprobatorio, cuando menos, de catorce magistrados. 
c) Se crea el amparo de una sola instancia contra las sentencias de los tribunales administrativos, cuyos fallos se asimilan a los de los tribunales ordinarios, ya que con anterioridad se estimaban como actos formalmente administrativos y se impugnaban a través del amparo de doble instancia ${ }^{50}$.

d) Se conserva, no obstante las críticas, la carga de impulsión en los juicios de amparo administrativos y civiles, exceptuándose la inconstitucionalidad de las leyes y aquellos que versen sobre derechos individuales y colectivos de ejidatarios, comuneros y núcleos de población, pero se corrige el error de técnica de las reformas anteriores, de manera que además del sobreseimiento del juicio en primera o única instancia por inactividad del promovente del amparo, se introduce la caducidad de la instancia para el segundo grado, correspondiendo en este último la carga al recurrente y con la consecuencia de quedar firme la sentencia de primera instancia, y se amplía en cualquier caso el plazo de promoción a trescientos días incluyendo los inhábiles (artículos 107, fracción XIV de la Carta Federal y 74, fracción V, de la Ley de Amparo).

e) Se extiende el ámbito de la jurisprudencia obligatoria de los tribunales Federales, no solamente respecto de la Suprema Corte de Justicia en asuntos de amparo, sino también a los de carácter ordinario, así como en relación con las tesis sustentadas por los tribunales colegiados de circuito, y comprende la interpretación de la Constitución, leyes federales y tratados, así como la de las leyes locales, que anteriormente estaba excluída, con lo cual culmina en forma abierta la centralización judicial (artículo 94 de la Constitución Federal y 192 a 197 de la Ley de Amparo y 95 de la Ley Orgánica del Poder Judicial Federal) ${ }^{\mathbf{5 1}}$.

c) Se restringe la competencia del Tribunal en Pleno de la Suprema Corte de Justicia para conocer de los juicios en que la Federación es parte, exclusivamente a aquellos en los que el mismo Pleno las considere de importancia trascendente para los intereses de la Nación (artículo 105 constitucional y 11, fracción IV, de la Ley Orgánica del Poder Judicial Federal), en virtud de que la jurisprudencia había sido muy variable, y que en ocasiones el propio Tribunal en Pleno estaba obligado a resolver controversias entre particulares y autoridades federales, de escasa importancia económica o jurídica ${ }^{52}$.

20. Tomando en cuenta el propósito de reducir el rezago de la Suprema Corte de Justicia, las citadas reformas que entraron en vigor en octubre de 1968, han sido bastante efectivas, si se toma en consideración que de los quince mil asuntos - sin contar los del Tribunal en Pleno- que se encontraban en las Salas antes de esa fecha, trece mil fueron turnados a los Tribunales Colegiados de Circuito, de manera que la propia Corte conservó sólo dos mil; y por otra parte se aumentó el

\footnotetext{
50 En la exposición de motivos de la iniciativa presidencial de 1965 , se sostuvo al respecto: *Si en términos de la fracción III del artículo 107 en vigor, las reglas sobre procedencia del amparo en materia judicial se aplican a las del trabajo, lógicamente debe quedar también sujeto a esas reglas el amparo contra tribunales administrativos, ya que los procedimientos que éstos instruyen, al igual que los seguidos ante los tribunales del trabajo, lo son en forma de juicio. De ahí la reforma que se propone de la mencionada fracción III para que las mismas normas de procedenca rijan el amparo contra tribunales judiciales administrativos y del trabajo y la fracción IV seguirá regulando el amparo en materia administrativa contra resoluciones no dictadas por tribunales..."

$51 \mathrm{Es}$ significativo advertir que las reglas sobre la jurisprudencia obligatoria estaban situadas a partir de la reforma de 1951, en la fracción XIII del artículo 107 de la Carta Federal, y por tanto se aplicaba exclusivamente a la materia de amparo, pero en las modificaciones que entraron en vigor en el mes de octubre de 1968, si situó la regla respectiva en el artículo 94 de la misma Constitución Federal, en los siguientes términos: „La ley fijará los términos en que sea obligatoria la jurisprudencia que establezcan los Tribunales del Poder Judicial de la Federación sobre interpretación de la Constitución, leyes y reglamentos federales o locales y tratados internacionales celebrados por el Estado Mexicano, así como los requisitos para su interrupción y modificació ..."

52 Cfr. Héctor Fix-Zamudio, Algunas consideraciones respecto a las reformas constitucionales, cit., p. 45.
} 
número de los tribunales colegiados, de seis (dos en el Distrito Federal) a trece, distribuídos en ocho circuitos -en vez de los cinco anteriores- en la inteligencia de que en la ciudad de México se establecieron cinco tribunales colegiados divididos por materias, (penal, dos administrativos, dos civiles, y del trabajo).

21. Estimamos que las reformas anteriores, que son las que se encuentran actualmente en vigor, han producido el efecto de aliviar a la Suprema Corte del enorme peso que la abrumó por mucho tiempo, lo que es posible comprobar si realizamos un análisis de la situación en los últimos veinticinco años.

En efecto, en el año de 1950, con anterioridad a las reformas que entraron en vigor en 1951, el organismo judicial federal estaba integrado con la Suprema Corte de Justicia, formada por veintiún magistrados, funcionando en Pleno y en cuatro Salas de cinco; y cuarenta y seis juzgados de Distrito, distribuidos en toda la República con órganos de primera instancia en materia ordinaria federal y de amparo.

En 1951, según se ha visto, se crearon cinco tribunales colegiados, conservándose el mismo número de cuarenta y seis jueces de Distrito. Además se designaron cinco magistrados supernumerarios en la Suprema Corte de Justicia, que funcionaron varios años también como Sala Auxiliar.

Finalmente, en 1975, además de las cuatro salas numerarias de la Suprema Corte y los cinco magistrados que integran la Sala Auxiliar, existen diecisiete tribunales colegiados, de los cuales siete se encuentran en la ciudad de México divididos por materias (tres administrativos, dos civiles, uno penal y otro del trabajo); y sesenta y tres jueces de Distrito, de los cuales diez tienen su residencia en la propia ciudad de México, también divididos por materias (cuatro administrativos, cuatro penales y dos civiles).

Por lo que se refiere a los asuntos pendientes de resolución en la Suprema Corte de Justicia, en el año de 1950 ascendían a treinta y siete mil ochocientos ochenta y uno ${ }^{53}$, en tanto que en el otro extremo, en 1975, sólo llegan a dos mil ochocientos veintitrés, lo que nos indica un descenso considerable en el rezago de los asuntos del conocimiento del más Alto Tribunal de la República ${ }^{54}$.

En cuanto a los asuntos pendientes de resolución en los juzgados de Distrito en el citado año de 1950, llegaban a la suma de veintisiete mil doscientos setenta y uno, a los cuales debían agregarse setecientos ochenta y dos juicios ordinarios pendientes de apelación en los tribunales unitarios de circuito; todos los cuales sumados a los existentes en la Suprema Corte en esa época, hacían ascender la suma total de procesos ordinarios y de amparo pendientes en los tribunales federales en el año de 1950, a la suma elevadísima de setenta y cinco mil novecientos treinta y cuatro.

Por el contrario, si pasamos revista a los asuntos pendientes en los tribunales colegiados de circuito (seis mil ciento once, todos ellos en materia de amparo); en los tribunales unitarios de circuito (dos mil setecientos setenta y ocho); y en los juzgados de Distrito (diecisiete mil novecientos sesenta y siete), que unidos a los de la Suprema Corte, hacen un total de veintinueve mil seiscientos setenta y nueve), al finalizar el año de 1975; lo que indica que un alivio considerable respecto del rezago existente veinticinco años antes, aun cuando se advierte que si bien la Suprema Corte se ha desahogado considerablemente, el recargo ha pasado a los

53 Véase Informe de Labores de la Suprema Corte de Justicia, correspondiente al año de 1950, pp. $142-143$. 54 Véase Informe de Labores de la Suprema Corte de Justicia, del año de 1975, cuadros estadísticos. 
tribunales colegiados y en especial a los juzgados de Distrito, no obstante que su número se ha incrementado considerablemente.

Todo lo anterior nos lleva a la conclusión de que, en la actualidad y después de dos reformas constitucionales, se ha resuelto en forma relativa el problema del rezago, al menos en la Suprema Corte de Justicia, pero no se han atendido otros problemas fundamentales de la administración de la justicia federal, como lo señalaremos al hacer el balance de la situación actual del citado organismo judicial.

\section{El desarrollo de los tribunales administrativos}

22. Tanto por influencia del derecho angloamericano, particularmente el de los Estados Unidos, como por la tradición hispánica de la época colonial55, en nuestro país se adoptó la corriente judicialista en cuanto a la impugnación de los actos y resoluciones de la administración activa, es decir, que sólo podían combatirse ante los tribunales ordinarios, tanto en el ámbito federal como en los ordenamientos de las Entidades Federativas, pero a través de la Ley de Justicia Fiscal de 26 de agosto de 1936, se creó el Tribunal Fiscal de la Federación, situado formalmente dentro de la esfera de la administración federal, como órgano de justicia delegada, que debía dictar sus fallos en representación del Ejecutivo de la Unión ${ }^{56}$; y la misma situación se conservó en el Código Fiscal de 30 de diciembre de 193857, aun cuando se fueron incrementando las controversias que prodían ser conocidas por el citado tribunal, con lo cual su competencia resultó más amplia que la de un órgano de justicia tributaria en sentido estricto ${ }^{58}$.

23. Desde la creación del citado tribunal fiscal federal hasta el 30 de diciembre de 1946, en que se reformó la fracción I del artículo 104 constitucional para establecer un recurso de apelación federal contra resoluciones de tribunales administrativos federales ante la Segunda Sala de la Suprema Corte de Justicia ${ }^{59}$, que se reglamentó con el nombre de "revisión fiscal" como instrumento de impugnación contra los fallos del citado Tribunal Fiscal Federal60; se discutió apasionadamente en la doctrina sobre la constitucionalidad de dicho órgano de justicia administrativa, ya que un sector de tratadistas consideraba que no podía delegarse en un organismo administrativo la resolución de las controversias entre las autoridades fiscales y los causantes, que debían someterse forzosamente a los tribunales ordinarios federales, como se había venido haciendo con anterioridad ${ }^{61}$.

55 Cfr. Héctor Fix-Zamudio, Organización de los tribunales administrativos, en "Cuarto Número Extraordinario de la Revista del Tribunal Fiscal de la Federación”, México, 1971, p. 99.

56 En la parte relativa del artículo primero de la Ley de Justicia Fiscal de 27 de agosto de 1936, se dispuso "El Tribunal Fiscal dictará sus fallos en representación del Ejecutivo de la Unión, pero será independiente de la Secretaría de Hacienda y Crédito Público y de cualquiera otra autoridad administrativa".

57 Según el artículo 146 del Código Fiscal de 30 de diciembre de 1938, “El Tribunal Fiscal dictará sus fallos en representación del Ejecutivo de la Unión, pero será independiente de la Secretaría de Hacienda y Crédito Público y de cualquiera otra autoridad administrativa".

58 Cfr. Dolores Heduán Virués, Cuarta Década del Tribunal Fiscal de la Federación, México, 1971, pp. 51-62.

$59 \mathrm{El}$ texto de la citada reforma constitucional expresó: "En los juicios en que la Federación esté interesada, las leyes podrán establecer recursos ante la Suprema Corte de Justicia contra las sentencias de segunda instancia o contra las de tribunales administrativos creados por ley federal, siempre que dichos tribunales esté dotados de plena autonomía para dictar sus fallos".

60 Este recurso fue reglamentado, respecto de las autoridades fiscales federales, por la ley de 30 de diciembre de 1946, reformada el 30 de diciembre de 1949; y tratándose de las autoridades hacendarias del Distrito Federal, por la ley de 28 de diciembre de 1948, reformada el 30 de diciembre de 1950 , cfr. Héctor Fix-Zamudio, Introducción al estudio del proceso tributario en el derecho mexicano, en la obra "Perspectivas del derecho público en la segunda mitad del siglo XX", tomo III, Madrid, 1959, pp. $1131-1133$.

61 Cfr. Gabino Fraga, Derecho administrativo, 15a. Ed., México, 1973, pp. 469-476; Andrés Serra Rojas, Derecho administrativo, 6a. Ed., $2^{\circ}$ tomo, México, 1974, pp. 518-522. 
Sin embargo, y con independencia de esta discusión, los fallos del citado tribunal podían impugnarse en amparo si eran desfavorables a los administratados, y antes de 1946 no podían ser combatidos por las autoridades fiscales, ya que la jurisprudencia estimó que les esteba vededa la vía del amparo ${ }^{62}$, siendo esta la razón por la cual la Secretaría de Hacienda logró la aprobación de la citada reforma del artículo 104 constitucional, con el objeto de contar con un medio de impugnación, la revisión fiscal, contra las resoluciones del mismo tribunal fiscal contrarias a sus intereses.

24. En el año de 1950 nadie discutía la constitucionalidad del citado tribunal fiscal, debido a la reforma de 1946 que hemos citado tantas veces, e inclusive se hicieron intentos en algunas entidades federativas para establecer tribunales de carácter tributario en el ámbito local, y al respecto podemos citar los tribunales fiscales de Tamaulipas (1951); Colima (1955) y Guanajuato (1962), que no lograron consolidarse ${ }^{63}$.

No obstante, hasta las reformas de 1968 que hemos mencionado con anterioridad, la jurisprudencia de la Suprema Corte estimó que las sentencias del Tribunal Fiscal de la Federación y las de los que eventualmente pudieran crearse dentro de la esfera de la administración, debían considerarse comprendidas dentro de lo dispuesto por el artículo 114, fracción II, de la Ley de Amparo64, y por tanto debían impugnarse por parte de los particulares - las autoridades sólo por conducto de la llamada revisión fiscal a partir de 1946- en el juicio de amparo de doble instancia, la primera ante los jueces de distrito y la segunda ante la sala administrativa de la Suprema Corte de Justicia (artículo 84, fracción I, inciso b) de la misma Ley de Amparo), por considerarse una resolución administrativa y no de carácter judicial, lo que debemos considerar como un criterio en extremo formalista ${ }^{65}$.

25. Las mencionadas reformas constitucionales y legales que entraron en vigor en el mes de octubre de 1968, han favorecido notoriamente al establecimientos de tribunales administrativos, en un doble sentido:

a) En primer lugar, se adicionó el artículo 104, fracción I, de la Constitución Federal, para disponer que: "Las Leyes federales podrán instituir tribunales de lo contencioso-administrativo dotados de plena autonomía para dictar sus fallos, que tengan a su cargo dirimir las controversias que se susciten entre la La Administración Pública Federal o del Distrito Federal, y los particulares, estableciendo normas para su organización, su funcionamiento, el procedimientro y los recursos contra sus resoluciones".

Esta disposición tiene su antecedente en la Ley Orgánica del Tribunal Fiscal de la

$62 \mathrm{La}$ tesis 183, páginas 317-318, Segunda Sala, del Apéndice al Semanario Judicial de la Federación publicado en el año de 1975, afirma en su parte conducente que: "El Fisco cuando usa de su facultad soberana de cobrar impuestos, multas y otros pagos fiscales obra ejerciendo una prerrogativa inherente a su soberanía, por lo cual no puede concebirse que el Poder pida amparo en defensa de un acto del propio Poder

63 Cfr. Héctor Fix-Zamudio, Introducción al estudio del proceso tributario en el derecho mexicano pp. $1055-1062$.

64 El texto original del citado artículo 114, fracción II, de la Ley de Amparo, disponía: "El amparo se pedirá ante el Juez de Distrito: II. Contra actos de autoridades distintas de las judiciales o de las Juntas de Conciliación y Arbitraje. En estos casos, cuando el acto reclamado emane de un procedimiento seguido en forma de juicio ante dichas autoridades, el amparo sólo podrá promoverse contra la resolución definitiva por violaciones cometidas en la misma resolución o durante el procedimiento, si por virtud de estas últimas hubiere quedado sin defensa el quejoso o privado de los derechos que la misma ley de la materia le conceda, a no ser que el amparo sea promovido por persona extraña a la controversia".

65 Véasela parte relativa de la exposición de motivos de la iniciativa presidencial de noviembre de 1965 , que propuso la creación del amparo de una sola instancia contra sentencias de los tribunales administrativos, en la nota 50 de este trabajo. 
Federación que entró en vigor el 10 de abril de 1967, en cuyo artículo primero se estableció la plena autonomía del propio Tribunal, abandonando así el sistema de jurisdicción delegada de los ordenamientos anteriores, por lo que ya resulta dusoso que dicho organismo pueda considerarse formalmente administrativo, sino tribunal federal, aun cuando independiente de los de carácter ordinario, en forma similar a lo que ocurre en Uruguay y en la República Federal de Alemania'66.

Precisamente con apoyo en el precepto constitucional antes transcrito, se expidió la Ley del Tribunal de lo Contensioso-Administrativo del Distrito Federal de 20 de febrero de 1971, reformada el 2 de enero de 1973, estableciendo un organismo judicial, también dotado de plena autonomía, para resolver las controversias entre la administración pública del Distrito Federal y los administrados, con excepción de las de carácter tributario, que están encomendadas al Tribunal Fiscal de la Federación ${ }^{67}$.

Aun cuando no en forma tan amplia, pero sí también respecto de la materia tributaria, se han establecido tribunales fiscales en el Estado de México (1971), ${ }^{68}$ y en el Estado de Veracruz (1975) ${ }^{69}$.

Por otra parte en la esfera federal ya se advierte la tendencia a la creación de un tribunal de justicia administrativa en sentido amplio, tomando como base el fiscal ya existente, pero ampliando su competencia para conocer de todas las controversias entre la administración federal y los administrados, y en esta dirección podemos señalar el proyecto elaborado en el año de 1964 por varios magistrados del Tribunal Fiscal70, y uno nuevo redactado por el mismo Tribunal Fiscal a iniciativa de su Presidente, en el año de 1973, también para ampliar la jurisdicción del citado organismo judicial con el objeto de establecer un Tribunal Federal de Justicia Administrativa, con la característica de que se propone desconcentrar las Salas para situarlas en varias regiones del país ${ }^{71}$.

b) El segundo aspecto importante de la reforma que entró en vigor en 1968, radica en el reconocimiento de sentencia judicial para las resoluciones del Tribunal Fiscal de la Federación y de los restantes tribunales administrativos, de tal manera que a partir de entonces, dichos fallos deben impugnarse a través del juicio de amparo de una sola instancia, ya sea ante la Suprema Corte de Justicia o los Tribunales Colegiado de Circuito, según la importancia económica o jurídica del asunto (la base esencial es la cuantía de quinientos mil pesos para la competencia de la Corte), amparo que pueden interponer los particulares afectados, ya que las autoridades no pueden promover dicho juicio, a no ser en forma limitada contra los fallos del propio Tribunal Fiscal, por conducto de la revisión fiscal, que ha sido restringida en forma considerable según las disposiciones del Código Fiscal de 1967 y el artículo 104, fracción I, de la Constitución Federal, en su reforma ya mencionada de $1968^{72}$.

66 Cfr. Klaus Vogel, La tutela jurídica frente al poder público en la República Federal de Alemania, trad. de José Luis Barrios, en "La Revista de Derecho, Jurisprudencia y Administración”, Montevideo, 1968, pp. 153-168; Horacio Cassinelli Muñoz, Confrontación entre los sistemas de lo contencioso administrativo en Alemania Federal y en Uruguay, en la misma Revista, pp. 153-168.

67 Cfr. Humberto Briseño Sierra, La competencia del Tribunal de lo contencioso-administrativo, en "Revista del Tribunal de lo Contencioso Administrativo del Distrito Federal", Núm. 1, México, julio de 1972, pp. 7-26.

68 Establecido en el Código Fiscal del Estado de México, de 31 de diciembre de 1970, artículos 158-209.

69 Establecido por la Ley Núm. 85, de 29 de diciembre de 1975, denominada Ley Orgánica del Tribunal Fiscal del Estado de Veracruz-Llave.

70 Cfr. Dolores Heduán Virués, Cuarta década del Tribunal Fiscal de la Federación, cit., pp. $305-319$.

$71 \mathrm{Cfr}$. Gonzalo Armienta Calderón, El proceso tributario en el derecho mexicano, actualmente en prensa, pp. 459-463 del ejemplar mimeografiado.

72 Cfr. Dolores Heduán Virués, Cuarta década del Tribunal Fiscal, cit., pp. 281-286. 
26. En términos generales podemos afirmar que en estos veintincinco años se ha vigorizado considerablemente la justicia administrativa, primero a través de un solo tribunal federal exclusivamente tributario y de jurisdicción delegada, cuya competencia se fue ampliando paulatinamente, pero a partir de 1967, y con mayor razón con la reforma que entró en vigor en 1968, con tribunales autónomos aún cuando independientes de los tribunales ordinarios, con la tendencia hacia la creación de órganos de justicia administrativa de carácter general, según el modelo del Tribunal de lo Contencioso Administrativo del Distrito Federal, establecido en el año de 1971.

Sin embargo no se ha dado otro paso importante, o sea el relativo al reconocimiento de la imperatividad de las resoluciones condenatorias de los citados tribunales, ya que todavía en la actualidad se considera, tomando como modelo el criterio de la Ley de Justicia Fiscal de 1936, expedida en una época muy diferente a la actual, que los tribunales administrativos no pueden ejecutar sus fallos, los que se dejan a la buena voluntad de las autoridades administrativas, y en caso de negativa, queda abierto el camino para hacer valer un juicio de amparo contra la inejecuciôn, lo que nos parece excesivo, aun tomando en cuenta las dificultades del cumplimiento de las sentencias administrativas ${ }^{73}$.

\section{Los tribunales de familia y los consejos tutelares de menores}

27. A) Aun cuando no derivaron de una reforma constitucional, sin embargo es preciso mencionar dos aspectos importantes de la evolución del organismo judicial del Distrito Federal, que experimentó importantes modificaciones al introducirse los tribunales de familia en el año de 1971, y la sustitución de los tribunales de menores por los consejos tutelares, en 1973.

a) Por lo que se refiere a los tribunales de familia constituyen un paso importante en la configuración de organismos judiciales especializados en las materias crecientemente complejas de las relaciones jurídicas de nuestra época, especialmente tratándose de la resolución de las cuestiones familiares cada vez más difíciles y cuyo conocimiento se distribuía anterioremente entre los llamados juzgados pupilares y los jueces de primera instancia en materia civil, pero cuya ineficacia era patente ${ }^{74}$.

La reforma se realizó en dos etapas; en la primera se crearon los juzgados de lo familiar en primera instancia, y Salas especializadas en el Tribunal Superior de Justicia del Distrito Federal, a través de las modificaciones introducidas en el año 1971, a la Ley Orgánica de los Tribunales del Fuero Común del Distrito Federal, de 26 de diciembre de 1968.

\footnotetext{
73 Cfr. Jesús González Pérez, La inejecución de las sentencias administrativas, en «Revista de la Facultad de Derecho de México", Núm. 91-92, julio-diciembre de 1973, p p. 421-436.

74 Esta situación fue la que determinó la iniciativa presidencial de 29 de diciembre de 1970 , en cuya exposición de motivos, se expresó en la parte relativa: "Alrededor de la niñez, la juventud, la familia y de aquellos que por su estado de salud o por sus hábitos están imposibilitados para manejar sus propios intereses, se producen graves conflictos que exigen la intervención judicial. Hasta el momento, salvo algunas cuestiones encomendadas a los jueces pupilares, el manejo de esos problemas de derecho de familia ha quedado a cargo de los jueces civiles. Sin embargo, para ser congruentes con la tendencia de considerar como un todo armónico el derecho de familia, y para poder atender estas cuestiones conflictivas con la técnica adecuada, hemos considerado conveniente que la autonomía que se apunta, impartición de la justicia en la medida en que se haga por jueces especializados, los que habrán de dedicar todo su esfuerzo al conocimiento de los conflictos familiares, haciendo abstracción de los demás problemas civiles y mercantiles que ahora absorben la mayor parte de su tiempo ..."
} 
$\mathrm{Si}$ bien estas reformas recogieron las inquietudes hacia el establecimiento de organismos judiciales especializados que toman en cuenta la evolución del derecho familiar, el que inclusive en el campo sustantivo tiende a adquirir caracteres peculiares, dentro del derecho privado ${ }^{75}$, no se tomaron en cuenta las experiencias de otros países latinoamericanos, especialmente la Ley de Tribunales de Familia de Guatemala, según Decreto-Ley Número 206, de 7 de mayo de $1964^{76}$, y por ello, si bien debe considerarse un adelanto respecto a la situación anterior en la que imperaba el descuido de las relaciones familiares, se incurrió en el grave error de conferir a dichos tribunales mexicanos de lo familiar competencia, no sólo respecto de controversias sobre las relaciones familiares y del estado civil, capacidad de las personas y derivadas del parentesco ${ }^{77}$; sino todo lo relativo a los juicios sucesorios, que sólo de manera muy forzada pueden vincularse directamente con las cuestiones de familia, por lo que se desvirtúa totalmente la función de los citados juzgados, tomando en cuenta la profusión de procedimientos y controversias sucesorias que se tramitan en el Distrito Federal78; y por otra parte, tampoco se ha dotado a dichos juzgados de lo familiar con el personal técnico indispensable para la realización de sus funciones, tales como médicos psicólogos, trabajadores sociales, o al menos con estos últimos ${ }^{79}$, por lo que es posible afirmar que sólo se ha dado un paso muy vacilante en esta materia tan importante.

b) La segunda etapa en cuanto a la resolución de las controversias familiares consistió en la introducción de un título especial en el Código de Procedimientos Civiles para el Distrito Federal, que se refiere precisamente a las controversias de orden familiar, por ley de 26 de febrero de 1973, y a la que nos referiremos al hablar de las reformas procesales durante el período que estamos analizando.

B) La introducción de los consejos tutelares para menores infractores en el Distrito Federal se produjo por la ley de este nombre, promulgada el 26 de diciembre de 1973, que recoge las experiencias de algunos ordenamientos locales y también de Latinoamérica ${ }^{80}$, habiendo sustituído a la Ley Orgánica y Normas de Procedimiento de los Tribunales de Menores y sus Instituciones Auxiliares en el Distrito y Territorios Federales, de 22 de abril de 1941, y derogando varias disposiciones del Código Penal para el propio Distrito Federal.

75 Cfr. entre otros, José Barroso, La autonomía del derecho de familia, en "Revista de la Facultad de Derecho de México”, Núm. 68, octubre-diciembre de 1967, pp. 809-843.

76 Cfr. Mario Aguirre Godoy y Carlos Enrique Peralta Méndez, Código Procesal Civil y Mercantil y otras leyes vigentes, Guatemala, 1973, pp. 193-197, y además el Instructivo para los Tribunales de Familia, expedido por la Corte Suprema de Justicia de 9 de septiembre de 1964, pp. 197-202.

77 En general, el artículo 58 de la Ley Orgánica de los Tribunales de Justicia del Fuero Común del Distrito Federal, establece la competencia de los tribunales de lo familiar para los problemas relativos al derecho de familia, y en la fracción VII se establece que dichos tribunales deben conocer ${ }^{\alpha} \mathrm{De}$ las cuestiones relativas a los asuntos que afecten en sus derechos de persona a los menores e incapacitados, así como todas las cuestiones familiares que reclamen la intervención judicial", pero en cambio la fracción III de dicho precepto introduce el elemento perturbador, al conferir a los propios organismos jurisdiccionales la facultad para conocer de los juicios sucesorios.

78 En nuestra intervención en la Cámara de Senadores cuando se discutía la referida iniciativa presidencial para la creación de los tribunales de lo familiar, señalamos los inconvenientes de conferir a dichos tribunales los problemas sucesorios, véase el libro editado por el Senado de la República, El proceso legislativo de la ley que establece las normas mínimas sobre readaptación social de los sentenciados, de procedimientos penalis del Distrito Federal, Federal de procedimientos penales, civil y de procedimientos civiles, y la Ley Orgánica de Tribunales del Fuero Común del Distrito Federal, México, 1971, pp. $249-250$.

79 De acuerdo con el artículo 56 de la Ley Orgánica de Tribunales del Fuero Común del Distrito Federal, los jueces de lo familiar contarán con el mismo personal que los juzgados de lo civil, señalado en el diverso artículo 61, por lo que se hace necesario una reforma legislativa para dotar a los primeros con el personal técnico necesario, de trabajadores sociales, pedagogos, médicos, psicólogos, etc., como también hicimos notar en la intervención señalada en la nota anterior, pp. 248-249.

$80 \mathrm{Cfr}$. José Ovalle Fabela, La Ley que crea los Consejos Tutelares para menores infractores del Distrito Federal, en "Gaceta Informativa de legislación y Jurisprudencia", Núm. 12, México, octubre-diciembre de 1974, pp. 693-698. 
Los citados Consejos Tutelares tienen fundamentalmente como objeto promover la readaptación social de los menores de dieciocho años, cuando infrinjan las leyes penales, los reglamentos de policía y buen gobierno, o manifiesten otra forma de conducta que haga presumir, fundadamente, una inclinación a causar daños a sí mismos, a su familia o a la sociedad, que ameriten la actuación preventiva de los propios Consejos. El Consejo Tutelar funciona en Pleno formado por dos consejeros integrantes de las Salas y un Presidente licenciado en Derecho, y en Salas formadas por un médico, un profesor especializado en infractores y su Presidente, licenciado en Derecho. El Pleno puede disponer el establecimiento de Consejos Tutelares Auxiliares en las delegaciones políticas del Distrito Federal, con presidente licenciado en Derecho y dos consejeros vocales aunque no tengan título (Art. 16). Los Consejos Tutelares pueden imponer las medidas de seguridad de carácter preventivo o de readaptación que se consideren necesarias, incluyendo también internamiento, libertad vigilada o colocación en un hogar sustituto, en la inteligencia de que las medidas pueden ser revisadas de oficio cada tres meses por el organismo respectivo, 0 antes, si existen circunstancias que lo exijan ${ }^{81}$.

Estas instituciones que no son estrictamente jurisdiccionales, sin embargo deben realizar una labor muy importante en el campo de la delincuencia juvenil, que constituye uno de los problemas más complejos de las ciudades modernas, y a nuestro modo de ver, doben considerarse como un adolento respecto de los tribunales de menores, ya que el espíritu de los nuevos Consejos, con acento en el carácter preventivo de sus funciones, pueden tener una eficacia superior a los tribunales anteriores, aun cuando todavía es demasiado pronto para poder emitir un juicio sobre sus funciones.

\section{El Ministerio Público y la defensoría de oficio.}

28. Si bien estas dos instituciones, que deben colaborar con el juzgador para la resolución de las controversias que le son encomendadas, no forman parte en nuestro país del organismo judicial, sin embargo, debemos considerarlas inseparables de la prestación jurisdiccional y por ello hacemos una breve referencia a su desarrollo en estos últimos veinticinco años.

A. Por lo que se refiere al Ministerio Público, como es bien sabido y debido al criterio del Constituyente de 1916-1917, que pretendió corregir los vicios del juez de instrucción de los ordenamientos anteriores a la revolución ${ }^{82}$, en el artículo 21 de la Constitución federal se le atribuye en forma exclusiva la función persecutoria de los delitos, y además, de acuerdo con la interpretación que se ha hecho en los respectivos códigos procesales penales y por la jurisprudencia, se le otorga el monopolio del ejercicio de la acción penal, privando a la víctima o a sus causahabientes de toda intervención en el proceso penal en cuanto a la responsabilidad del acusado ${ }^{83}$.

\footnotetext{
81 Cfr. Sergio García Ramírez, Curso de derecho procesal penal, México, 1974, pp. 530_542.

82 En la exposición de motivos del proyecto de Constitución presentado por don Venustiano Carranza al Congreso de Querétaro el primero de diciembre de 1916, se expresó en lo conducente: “. . Los jueces mexicanos han sido, durante el periódo corrido desde la consumación de la independencia hasta hoy, iguales a los jueces de la época colonial: ellos son los encargados de averiguar los delitos y buscar las pruebas, a cuyo efecto siempre se han considerado autorizados a emprender verdaderos asaltos contra los reos, para obligarlos a confesar, lo que sin duda alguna desnaturaliza las funciones de la judicatura".

83 Cfr. Juventino V. Castro, El Ministerio Público en México, Funciones y disfunciones, México, 1976, pp. 100-129; Sergio García Ramírez, Curso de derecho procesal penal, cit. pp. 203-212.
} 
Por otra parte, también debemos señalar que en el artículo 102 de la misma Constitución Federal -que por otra parte está situado en el Capítulo IV del Título Segundo, relativo al poder judicial84 - se confiere al Procurador General de la República - y esto influye también en los funcionarios respectivos de las Entidades Federativas - la doble función, a nuestro modo de ver incompatible, de representante jurídico del gobierno federal y al mismo tiempo, la dirección del ministerio público federal, debido a una mezcla muy poco afortunada de instituciones disímbolas y con funciones diversas, como el Fiscal de las Audiencias de la época colonial, el Attorney General de los países angloamericanos, y del ministerio público francés ${ }^{85}$, y esto explica, que se conserve el criterio establecido en la reforma al artículo 96 de la Constitución Federal de 1857, en el sentido de que el Procurador General de la República - y en forma similar para los funcionarios equivalentes en las Entidades Federativas- es nombrado y removido libremente por el Ejecutivo de la Unión ${ }^{86}$.

En esta materia no se ha avanzado gran cosa en el período que examinamos ya que continúan los elementos esenciales ya mencionados y si bien se han expedido varias leyes reglamentarias de la institución, que establecen algunos avances en ciertos aspectos técnicos sobre la organización interna de las Procuradurías respectivas, no modifican la dependencia del ministerio público respecto del organismo ejecutivo, ni tampoco el monopolio que se le ha atribuído para el ejercicio de la acción penal.

a) Citaremos sólo en vía de ejemplo, que en materia federal, durante este período se expidieron dos ordenamientos, la Ley Orgánica del Ministerio Público Federal, de 10 de noviembre de 1955, y con una denominación más adecuada, la Ley de la rocuraduría General de la República, promulgada el 27 de diciembre de 1974.

Resulta más propio el segundo título de la ley que el primero, ya que se regulan las dos funciones esenciales, de persecución de los delitos y ejercicio de la acción penal, por una parte, y la asesoría jurídica del gobierno federal, por la otra; pero no descubrimos, fuera de la mayor precisión de las atribuciones del Procurador y de los funcionarios respectivos, así como una organizacion interna más adecuada de la segunda sobre la primera, un cambio que pueda considerarse sustancial en estas dos leyes federales.

Tal vez el único progreso digno de señalarse, en la ley de 1974, tomado del ordenamiento del Distrito Federal, según veremos, es el establecimiento del Instituto Técnico, con la función esencial de la selección y capacitacion del personal adminisTécnico, con la funcion esencial de la selección y capacitación del personal administrativo, técnico y profesional, tan necesaria en un medio como el nuestro en el cual ha imperado la improvisación en las funciones del ministerio público y de la policía judicial que dependen del mismo $-\mathrm{y}$ no como su nombre señala, del

84 La razón por la cual el precepto fundamental sobre el Ministerio Público Federal se encuentre situado en el Capítulo del Poder Judicial, tiene su origen en el texto primitivo del artículo 91 de la Constitución Federal de 1857 , que situaba al procurador general como miembro de la Suprema Corte de Justicia, y por tanto era electo en la misma forma que los magistrados de dicho tribunal, cfr. José M. del Castillo Velasco, Apuntamientos para el estudio del derecho constitucional mexicano, cit., pp. 196-199.

85 Cfr. Héctor Fix Zamudio El problema de la lentitud de los procesos y su solución en el ordenamiento mexicano, en "Revista de la Facultad de Derecho de México", Núm. 81-82, enero-junio de 1971,

86 En la parte relativa del artículo 96 de la Constitución Federal, tal como fue reformado el 22 de mayo de 1900, se estableció en la parte conducente: "Los funcionarios del Ministerio Público y el Procurador General de la República que ha de presidirlo, serán nombrados por el Ejecutivo”, cfr. Mariano Coronado, Elementos de derecho constitucional mexicano, cit., pp. 187-189. 
organismo judicial一, ya que no existe preparación especial ni oposiciones para ingresar en estas profesiones ${ }^{87}$.

b) En el Distrito Federal ha ocurrido algo similar, en el período que examinamos, pues se han expedido dos ordenamientos: la Ley Orgánica del Ministerio Público del Distrito y Territorio Federales, de 29 de diciembre de 1954, y la Ley Orgánica de la Procuraduría General de Justicia del Distrito y Territorios Federales, ahora sólo del Distrito Federal, promulgada el 2 de diciembre de 1971, pero de manera diferente a lo que normalmente se presenta en el orden nacional, los ordenamientos locales del Distrito Federal, han servido de ejemplo a la legislación para toda la República, y especialmente en cuanto a la ley de 1971, que indudablemente se tomó como modelo, en todo lo pertinente, para la Procuraduría General de la República.

En este sentido, el adelanto fundamental del citado ordenamiento del Distrito Federal de 1971, es el relativo al establecimiento del Instituto Técnico de la Procuraduría, que superó al Instituto de Capacitación Criminalística anterior, ya que el actual tiene como funciones esenciales la selección del personal del ministerio público y de la policía judicial, con criterios técnicos, y el establecimiento de cursos de perfeccionamiento inclusive a nivel superior, todo lo cual constituye el aspecto más importante, entre otros, de la excelente labor realizada por el distinguido jurista mexicano Sergio García Ramírez cuando estuvo al frente de la propia Procuraduría del Distrito Federal ${ }^{88}$.

b. Por lo que se refiere a los defensores de oficio como asesores de las personas carentes de medios para lograr el auxilio de un abogado - tomando en cuenta que formalmente están prohibidas las costas judiciales, y por lo tanto la justicia es gratuita según el artículo 17 constitucional ${ }^{89}$ - no hemos dado un solo paso adelante en los últimos veinticinco años.

a) En efecto, en materia federal la defensoría de oficio está regida por la ley de 30 de enero de 1922 y su reglamento fue expedido el 18 de octubre del mismo año, depende de la Suprema Corte de Justicia y está confiada a un jefe y al número de defensores que se consideren convenientes por la propia Corte ${ }^{90}$.

b) Por lo que se refiere al Distrito Federal, sólo cuenta con el reglamento de 7 de mayo de 1940, está dividido en dos sectores, en materia civil y penal, y la defensoría depende de las autoridades administrativas del Distrito Federal.

c) En las Entidades Federativas se han expedido varios ordenamientos, pero sólo un número reducido de los mismos son posteriores a 1950, y entre ellos podemos citar las leyes de defensoría de oficio de los Estados de México (1951), Baja California (1954); Michoacán (1953); Puebla (1957); Tamaulipas y Coahuila (1964) ${ }^{91}$.

d) En otro sector del ordenamiento jurídico y siguiendo una tradición de la época colonial ${ }^{92}$, los defensores se han calificado de procuradores, como los de la defensa del trabajo, reorganizados en la Ley Federal del Trabajo de 1970, tanto en la

87 Cfr. Sergio García Ramírez, Comentarios sobre la Ley Orgánica de la Procuraduría de Justicia del Distrito y Territorios Federales, en "Gaceta Informativa de Legislación y Jurisprudencia", núm. 7-8, México, julio-diciembre de 1973 , pp. 394-395.

88 Cfr. Sergio García Ramírez, op.ult.cit., pp. 379-397.

89 Cfr. Héctor Fix-Zamudio, Constitución y proceso civil en Latinoamérica, México, 1974, pp. 64-66.

90 Cfr. Sergio García Ramírez, Noticia sobre el defensor en el derecho mexicano, en el volumen “Comunicaciones mexicanas al VIII Congreso Internacional de Derecho Comparado”, México, 1971, pp. 398 -399.

91 Cfr. Sergio García Ramírez, op.ult.cit., pp. 399-404.

91 En cierta manera los procuradores en su función de defensores de personas que carecen de asesoramiento, provienen de los protectores de indios, del Capítulo VI, Libro Sexto, de la Recopilación de las Leyes de los Reinos de las Indias, tomo segundo, pp. 249-250 (ed. Madrid, 1841). 
esfera federal como local93, con cierta autonomía otorgada en 197594; los procuradores agrarios establecidos para toda la República en el año de 195495; y finalmente los promotores de menores consagrados en la ley de Consejos Tutelares del Distrito Federal de diciembre de $1973^{96}$.

29. Como puede observarse de la simple descripción anterior, la institución de la defensoría de oficio, incluyendo los llamados procuradores, se ha mantenido estática en sus rasgos tradicionales de la defensa estrictamente judicial de las personas carentes de recursos, y no se ha intentado ni siquiera el estudio para introducir instituciones más adecuadas a nuestra época, como el asesoramiento jurídico, no sólo en el ámbito procesal, sino también en cuanto al consejo legal en una serie de aspectos que en número creciente requieren de un apoyo técnico del cual evidentemente carecen las personas de menores, e inclusive, de ingresos medios, de acuerdo con la evolución que en muchos países inclusive ha llevado a la asesoría jurídica al nivel de institución de seguridad social97.

\section{La evolución procesal}

30. Desafortunadamente en estos veinticinco años no advertimos un intento serio por renovar nuestros códigos claramente tradicionales tanto en materia de enjuiciamiento civil como penal, y las reformas que se han presentado todavía deben considerarse como muy tibias, en ocasiones con graves errores técnicos que las desvirtúan, y por ello no podemos considerar que nos hemos incorporado a la modernización de los códigos procesales latinoamericanos, al menos los de carácter civil, como ha ocurrido con el Código Civil y Mercantil de Guatemala de 196498; el Código Civil y Comercial de la Nación Argentina de 196799; el Código Procesal Civil colombiano de 1970100; y el Código Procesal Civil de Brasil, que entró en vigor en 1974101 .

31. Señalaremos brevemente algunos intentos para modernizar nuestros códigos procesales, que como lo ha demostrado claramente Niceto Alcalá-Zamora y Castillo, aun cuando tienen algunas diferencias de detalle y pueden agruparse en varias familias, sin embargo la mayor parte de ellos, los procesales civiles siguen el modelo del Distrito Federal y los penales toman como ejemplo al Federal102.

93 El Capítulo III, del Título Once, de la citada Ley Federal del Trabajo, artículos 530-536, regula la Procuraduría de Defensa del Trabajo.

94 Véase el Reglamento de la Procuraduría Federal de la Defensa del Trabajo, publicado en el “Diario Oficial de la Federación" el 2 de junio de 1975.

95 Cfr. Reglamento de la Procuraduría de Asuntos Agrarios, promulgado el 22 de julio de 1954.

96 Cfr. José Ovalle Favela, La Ley que crea los Consejos Tutelares para menores infractores del Distrito Federal, en "Gaceta Informativa de Legislación y Jurisprudencia”, Núm. 12, México, octubre-diciembre de 1974 , pp. 696.

97 Cfr. Héctor Fix-Zamudio, Breves reflexiones sobre el asesoramiento jurídico y procesal como institución de seguridad social, en el volumen "Libro de Homenaje a Luis Loreto", Caracas, 1975, pp. 577-611.

98 Cfr. Mario Aguirre Godoy y Carlos Enrique Peralta Méndez, Código Procesal Civil y Mercantil, cit., p p. 9-141, 248-522.

99 Cfr. Santiago Sentís Melendo, El nuevo Código Procesal Civil y Comercial de la Nación Argentina (Ley 17,454), en "Revista de Derecho Procesal Civil Iberoamericana”, Madrid, 1969, pp. 957-995.

100 Cfr. Hernando Devis Echandía, Progreso y deficiencias de la justicia civil en Colombia, en "Revista de Derecho Procesal Iberoamericana", Madrid, 1976, pp. 7-53.

101 Los comentarios sobre este código son muy numerosos, pero nos limitamos a señalar el breve pero profundo análisis de Niceto Alcalá-Zamora y Castillo, El nuevo Código Procesal Civil brasileño, en: “Gaceta Informativa de Legislación y Jurisprudencia”, Núm. 10, abril-junio de 1974, pp. $267-298$.

102 Cfr. Niceto Alcalá-Zamora y Castillo, Síntesis del derecho procesal, México, 1966, pp. $164-251$. 
a) En cuanto al enjuiciamiento civil al menos tres códigos locales se han inspirado en el Anteproyecto de Código del Distrito Federal de 1948, que sin abandonar los lineamientos tradicionales, sin embargo contiene así sea de manera limitada algunos elementos de renovación ${ }^{103}$, y estos ordenamientos fueron promulgados precisamente en el período que nos ocupa, y en esta dirección podemos señalar a los Códigos de Procedimientos Civiles de Sonora (1949); Morelos (1954) y Zacatecas (1966) ${ }^{104}$, y si bien se han expedido algunos otros códigos en este período, como los de Puebla de 1956, Tamaulipas en 1961, y recientemente el de Nuevo León de 1973, éstos poseen algunos aspectos peculiares, pero escasamente innovativos ${ }^{105}$.

b) El Código de Procedimientos Civiles del Distrito Federal ha sido objeto de varias reformas en este período, algunas de poca monta, y podemos citar como la más importante la de 26 de febrero de 1973, que ha recibido críticas bastante severas por parte de la doctrina ${ }^{106}$. Entre los aspectos esenciales de esa reforma podemos señalar, en primer término, la supresión del llamado juicio sumario, de manera que con excepción de los llamados procedimientos especiales, todas las controversias se tramitan en la llamada vía ordinaria; se pretende establecer de manera obligatoria el sistema oral de recepción de las pruebas, con lo cual se ha hecho el intento de atenuar el régimen desesperadamente escrito de nuestro procedimiento tradicional, por uno en el cual se desarrolle una oralidad más o menos atenuada, pero sin establecer las condiciones necesarias para su desarrollo, y por ello estimamos que este ensayo está destinado al fracaso ${ }^{107}$; y finalmente, un procedimiento para algunos aspectos de las controversias familiares, con algunos elementos dinámicos que superan el proceso civil tradicional, estableciendo el impulso oficial del procedimiento - incluyendo la posibilidad de la iniciación de oficio' ${ }^{108}$-; mayores facultades del juez para la dirección del proceso, pero sin realizar una verdadera transformación de sus atribuciones de manera que preda actuar como el verdadero director, y no como simple espectador del proceso ${ }^{109}$.

c) Respecto del proceso penal, podemos señalar como la innovación más importante en este período la reforma penal de 1971 en los ordenamientos sustantivos y adjetivos del Distrito Federal, y en la cual tuvo una participación destacada el jurista Sergio García Ramírez y que si bien se refirió en mayor extensión a la ejecución penal y al régimen penitenciario ${ }^{110}$, sin embargo introdujo el procedimiento sumario, de carácter voluntario para el inculpado y tratándose de delitos cuya pena máxima aplicable no exceda de cinco años de prisión (artículos

103 Sobre el citado anteproyecto, Curso Colectivo acerca del Anteproyecto de Código Procesal Civil para el Distrito Federal, en "Revista de la Escuela Nacional de Jurisprudencia", Núm. 47-48, México, julio-diciembre de 1950, pp. 9-266.

$104 \mathrm{Cfr}$. Niceto Alcalá-Zamora y Castillo, Unificación de los códigos procesales mexicanos, tanto civiles como penales, en "Revistade la Facultad de Derecho de México", Núm. 37-40, enero-diciembre de 1960, pp. 277-285.

105 Sobre el último, cfr. José Luis Soberanes Fernández, Nueva legislación adjetiva civil en el Estado de Nuevo León, en "Gaceta Informativa de Legislación y Jurisprudencia”, Núm. 506, México, enero-junio de 1973 , pp. $101-102$.

106 Cfr. entre otros, José Ovalle Favela, Las reformas al Código Procesal Civil del Distrito Federal y Territorios, en "Gaceta Informativa de Legislación y Jurisprudencia”, Núm. 5-6, México enero-junio de 1973, pp. 103-112, Miguel Angel y Jorge Hernándes Romo, La reforma procesal de 1973, en “Jurídica, Anuario del Departamento de Derecho de la Universidad Iberoamericana", Núm. 5, México, julio de 1973, pp. 297-323.

107 Cfr. entre otros, José Becerra Bautista, El proceso civil en México, 4a. Ed., México, 1974, pp. 157-166.

108 Cfr. José Becerra Bautista, Op.ult.cit., pp. 516-519.

109 Cfr. José Rodríguez U., Autoridad del juez y principio dispositivo, Valencia, Venezuela, 1968, así como el profundo prólogo a dicho libro redactado por Niceto Alcalá-Zamora y Castillo.

110 Cfr. Sergio García Ramírez, La reforma penal de 1971, México, 1971. 
305-312 del Código de Procedimientos Penales del Distrito Federal), y que se desarrolla o al menos debiera desarrollarse, en forma rápida y expedita11.

Este procedimiento sumario tiene su antecedente en una reforma de la legislación penal y procesal penal del Estado de Chihuahua en el año de 1969112.

También debemos tomar en cuenta que en la reforma a la Ley Orgánica de los Tribunales de Justicia del Fuero Común del Distrito Federal, efectuada en 1971, y a la cual hicimos referencia con anterioridad, se establecieron jueces unitarios de primera instancia en el propio Distrito Federal, en vez de las Cortes Penales existentes con anterioridad, como tribunales colegiados de tres jueces, todo ello con el objeto de agilizar el procedimiento que se ha vuelto muy lento en materia criminal113.

d) En el procedimiento laboral, si bien la Ley Federal del Trabajo de 1970 no modifica los aspectos tradicionales del procedimiento ante los tribunales paritarios, calificados todavía como Juntas de Conciliación y Arbitraje, sin embargo adopta algunos instrumentos más ágiles, con la preocupación esencial de agilizar el precedimiento que se ha vuelto sumamente lento y complicado precisamente contra los lineamientos básicos del enjuiciamiento laboral114, tales como la conciliación voluntaria ante las Juntas de Conciliación, la recepción anticipada de elementos de convicción ante los organismos citados; y, particularmente, una serie de reglas para evitar el principal obstáculo del desarrollo del procedimiento, que consistía en la desintegración de las Juntas como órganos paritarios, de manera que su presidente, que es realmente el juez profesional y técnico, se transforma en un verdadero juez instructor, que inclusive puede resolver varios aspectos procesales, y sólo para las resoluciones importantes y el llamado laudo, que es la sentencia de fondo, se debe contar con los representantes del capital y del trabajo, pero procurando su sustitución en caso de ausencia ${ }^{115}$.

e) En materia de amparo debemos señalar como importante la modificación de la fracción II del artículo 107 constitucional en el mes de octubre de 1962, y las reformas de la Ley de Amparo de enero de 1963, que establecieron en realidad un nuevo procedimiento que ha sido calificado como "juicio de amparo en materia

111 En la parte relativa de la exposición de motivos de la iniciativa de reformas al Código de Procedimientos Penales del Distrito Federal, presentada al Congreso de la Unión el 29 de diciembre de 1970, se expresa: Se distinguen dos formas de procedimiento: el sumario y el ordinario. Aquél significa una innovación en el Código, tiene lugar cuando existe flagrancia, y por lo mismo, menor dificultad probatoria y cuando no exceda de cinco años la pena máxima aplicable al delito de que se trata. En el procedimiento sumario, diseñado en forma tal que sea posible desarrollarlo con la mayor prontitud posible, se fijan plazos breves para el desarrollo de diversos actos procesales y se determina la concentración y la oralidad en la audiencia principal...”

112 Decreto 98-68 del Congreso del Estado de Chihuahua, promulgado el 2 de enero de 1969, se adicionaron los Códigos de Defensa Social y de Procedimientos en Materia de la Defensa Social en la citada entidad federativa, cfr. Héctor Fix-Zamudio, El problema de la lentitud de los procesos, cit., pp. 110-111.

113 En la exposición de motivos de la iniciativa de reformas al Código de Procedimientos Penales para el Distrito Federal, se expresó, en lo conducente, lo que sigue: "Entre las más importantes reformas contenidas en la iniciativa, figura la suprésión de las Cortes Penales, en forma tal que en lo sucesivo la justicia penal se impartirá sólo por órganos unitarios. Para esta reforma se han tomado en cuenta tanto las necesidades de mayor celeridad en la administración de justicia y de aumento de los órganos encargados de impartirla, como la conveniencia de que el proceso se desarolle íntegramente ante un mismo juez, pues de este modo se satisfacen mejor las exigencias de inmediación procesal y se favorece una más adecuada individualización de la pena. Además, el sistema de órganos unitarios ha probado sus virtudes en partidos de Villa Obregón, Coyoacán, y Xochimilco. Hoy día, no hay ninguna razón para que en el Distrito Federal coexistan dos sistemas jurisdiccionales, uno a base de juzgados colegiados y el otro de jueces unitarios..."

114 Una de las características que se ha señalado al proceso laboral moderno es precisamente su rapidez, para impedir que la parte trabajadora quede en situación económica angustiosa por la prolongación del proceso. Cfr. entre otros, Eduardo J. Couture, Algunas nociones fundamentales del derecho procesal del trabajo, en "Estudios de derecho procesal civil", tomo I, Buenos Aires, 1948, pp. 271 y ss., Miguel Rodríguez-Piñero, Derecho del trabajo y proceso, Madrid, 1972, pp. 5-10.

115 Cfr. Alberto Trueba Urbina, Nuevo derecho procesal del trabajo, 2a. Ed., México, 1973, pp. 421-429. 
agraria ejidal y comunal"116, que no hace otra cosa que introducir en el juicio de amparo administrativo, regido por el principio de "estricto derecho" del artículo 79 misma Ley de Amparo'117, los principios del proceso social, en el cual impera el llamado principio de "igualdad por compensación", que significa el otorgamiento privilegios procesales a la parte débil (trabajador, campesino, asegurado), respecto de su contraparte (empresario, terrateniente, instituciones de seguridad social), para lograr la verdadera igualdad de las partes en el proceso'118.

Sería sumamente difícil describir todas las ventajas procesales establecidas en beneficio de los ejidatarios, comuneros y núcleos de población ejidal o comunal, pero que se condensan esencialmente en la institución calificada "suplencia de la queja", que como aplicación del viejo principio de "iuris novit curia"11, obliga al juez a orientar a la parte débil, para allegarse o complementar elementos de convicción y llegar a una resolución justa de la controversia $-\mathrm{y}$ no simplemente legal-120.

Si bien en términos generales son acertadas las modificaciones de la ley de amparo según la reforma de 1963 en materia agraria ejidal y comunal, con algunos defectos técnicos fácilmente superables ${ }^{121}$, no se ha intentado una revisión a fondo de los restantes sectores del amparo, especialmente por lo que se refiere al amparo contra sentencias judiciales, que todavía mantiene en materia civil y administrativa la institución verdaderamente anacrónica del "amparo de estricto derecho", que constituye una verdadera reliquia en el proceso moderno ${ }^{122}$.

f) Respecto de los procedimientos agrarios, la Ley Federal de Reforma Agraria de 1971, conserva los antiguos procedimientos de dotación, restitución y aplicación de tierras, aguas y montes y de los conflictos de límites entre ejidos y comunidades, pero perfecciona algunos otros debido a la influencia del destacado jurista Lucio Mendieta y Núñez ${ }^{123}$, especialmente por lo que se refiere a la nulidad de actos y documentos agrarios, que resultaba indispensable debido a los problemas derivados de fraccionamientos simulados para evitar afectaciones, y expedición irregular de certificados de inafectabilidad ${ }^{124}$, que posteriormente repercuten en la impugnación a través del amparo interpuesto por los propietarios que ha estado bajo el ataque

116 Cfr. entre otros, Ignacio Burgoa, El juicio de amparo, cit., pp. 817-905; Luis del Toro Calero, El juicio de amparo en materia agraria (tesis), México, 1964.

117 El citado artículo 79 dispone: "La Suprema Corte de Justicia, los Tribunales Colegiados de Circuito y los jueces de Distrito, en sus sentencias, podrán suplir el error en que haya incurrido la parte agraviada al citar la garantía cuya violación reclame, otorgando el amparo por la que realmente aparezca violada, pero sin cambiar los hechos o conceptos de violación expuestos en la demanda. - El juicio de amparo por inexacta aplicación de la ley, contra actos de autoridades judiciales del orden civil, es de estricto derecho, salvo los casos de amparo que afecten derechos de menores o incapaces y, por tanto, la sentencia que en él se dicte, a pesar de lo prevenido por este artículo, se sujetará a los términos de la demanda, sin que sea permitido suplir ni ampliar nada en ella".

118 Cfr. Eduardo J. Couture, Algunas nociones fundamentales del derecho procesal del trabajo, cit., p. 272.

119 Cfr. entre otros, Santiago Sentís Melendo, El Juez y el derecho (Jura novit curia), Buenos Aires, 1957.

120 Cfr. Ignacio Burgoa, El juicio de amparo, cit., pp. 853-901.

$121 \mathrm{Se}$ le ha otorgado tal importancia a este sector del juicio de amparo, que ha merecido una reforma a la Ley de Amparo que fue publicada en Diario Oficial de la Federación el 29 de 1976, por la cual se divide la propia Ley de Amparo en dos libros, el primero intitulado "Del amparo en general" y el Segundo, "Del amparo en materia agraria" (en realidad ejidal y comunal), artículos 212-234, en el cual se incorporan las disposiciones introducidas en el año de 1963, que se encontraban distribuídas en las partes respectivas del mismo ordenamiento y que ahora se agrupan en este segundo libro.

122 Sobre la crítica del amparo de estricto derecho pueden consultarse los profundos estudios de Felipe Tena Ramírez, El amparo de estricto derecho y la suplencia de la queja, en el volumen "Problemas Jurídicos y Sociales de México", México 1955, pp. 27-40; y El amparo de estricto derecho: orígenes, expansión, inconvenientes, en "Revista de la Facultad de Derecho", Núm. 13, enero-marzo de 1954,

123 Cfr. Lucio Mendieta y Núñez y Luis G. Alcérreca Un anteproyecto de nuevo Código Agrario, México, 1964.

124 Cfr. Martha Chávez P. de Velázquez, El proceso social agrario y sus procedimientos, México, 1971, pp. 195-207; Humberto E. Ricord, Introducción jurídica a la reforma agraria mexicana, México, 1972, pp. $289-306$. 
de las organizaciones campesinas, las que pretenden la supresión del propio amparo, al cual achacan el retardo en la ejecución de las afectaciones agrarias ${ }^{125}$.

Pero tampoco nada se ha intentado o al menos no se han iniciado estudios, el establecimiento de una jurisdicción agraria, que es la tendencia que se observa en América Latina, como ha ocurrido en Bolivia (1952), Chile (1967) y Perú (1969)126, y se discute en el Congreso en Venezuela ${ }^{127}$, y cuya necesidad se ha señalado reiteradamente en nuestro país ${ }^{128}$.

\section{Situación actual del organismo judicial y perspectivas para el futuro}

32. De la desilvanada y superficial descripción de la evolución del organismo judicial, particularmente en el ámbito nacional y del Distrito Federal, en nuestro país, no es posible llegar a una conclusión muy alentadora, pues si bien en algunos sectores se advierte un cierto progreso, no podemos observar una verdadera preocupacion por adaptar la función jurisdiccional a la resolucion de las controversias cada vez más complejas, técnicas y numerosas de la complicada vida moderna.

1) Así, en las reformas al organismo judicial federal de 1951 y 1968, la preocupación fundamental radica en aliviar el rezago que periódicamente agobia en especial a la Suprema Corte de Justicia, y si bien prácticamente ha desaparecido dicho rezago en el más Alto Tribunal de la República a través de la una división de la competencia tomando en cuenta criterios patrimoniales, sociales y técnicos, y estableciendo tribunales colegiados de circuito, el recargo se ha trasladado actualmente a dichos tribunales y a los juzgados de Distrito ya que si el número pendiente de negocios no es tan elevado como en el año de 1950, no por ello deja de ser sustanciel, como se expresó en su oportunidad.

Pero no se ha logrado que se establezcan otras instituciones necesarias para la evolución del organismo judicial federal, y que se han recomendado en varios congresos mexicanos de derecho procesal, tales como una verdadera carrera judicial129; un sistema más flexible para la designación de los magistrados de la Suprema Corte de Justicia, el que funciona bastante bien en los Estados Unidos debido a los controles del Senado ${ }^{130}$, pero no ocurre en la misma forma en nuestro

125 Esta impugnación a la procedencia del amparo contra las resoluciones presidenciales dotatorias o restitutorias de tierras o aguas en beneficio de los campesinos que carecen de ellas no son algo nuevo, sino que se formularon insistentemente por los años treinta, determinando, como es bien sabido la reforma constitucional de 1934, que prohibió totalmente el amparo en esta materia de acuerdo con la fracción XIV del artículo 27 constitucional, que fue adicionada en 1947 para permitir la impugnación a través del juicio de amparo sólo por parte de los propietarios titulares de certificados de inafectabilidad, cfr. Ignacio Burgoa, El juicio de amparo, pp. 840-853; Humberto E. Ricord, op.ult.cit., pp. 308-309; Héctor Fix-Zamudio, Lineamientos fundamentales del proceso social agrario en el derecho mexicano, en "Revista de la Facultad de Derecho de México", Núm. 52 octubre-diciembre de 1963, pp. 922-924.

126 Cfr. J. Masrevery, Derecho agrario y reforma agraria, Roma, marzo de 1974, pp. 35-68.

127 Cfr. Miguel Angel Hernández O., y Román J. Duque Corredor, Estudios sobre jurisdicción agraria, Caracas, febrero de 1969.

128 Las iniciativas para establecer una jurisdicción agraria se remontan al Primer Congreso Nacional Revolucionario de Derecho Agrario, efectuado en la ciudad de México en el año de 1945, Memoria, pp. 326-329; y posteriormente en el Congreso Nacional Agrario de Toluca, efectuado en 1959, Memoria, p. 40; y más recientemente puede consultarse el breve pero sustancioso artículo de Raúl Cervantes Ahumada, Los tribunales agrarios (Necesidad de su creación), en "Estudios Agrarios", Cervantes Ahumada, Los tribunales agrari
Núm. 8, mayo-agosto de 1964, pp. 75-78.

$129 \mathrm{La}$ carrera judicial no se ha implantado en México no obstante las recomendaciones en este sentido aprobadas en el Primer Congreso Nacional y Segundas Jornadas Latinoamericanas de Derecho Procesal efectuados en esta ciudad en febrero de 1960, y Segundo Congreso Mexicano de Derecho Procesal reunido en Zacatecas en agosto de 1966, en "Revista de la Facultad de Derecho", 37-40, y 65, enero-diciembre de 1960 y enero-marzo de 1967, pp. 539-541 y 295-297, respectivamenté.

$130 \mathrm{Cfr}$. entre otros, Harold W. Chase, Federal Judges. The appointing process, en "Minnesota Law Review", diciembre de 1966, pp. 185-221. 
país, y si bien el sistema actual atribuye la designación a la exclusiva voluntad del Presidente de la República ${ }^{131}$; y el establecimiento de un organismo similar al Consejo Judicial o de la Magistratura para la designación, promoción y vigilancia de los jueces y magistrados federales ${ }^{132}$.

Por otra parte, coincidimos con Antonio Carrillo Flores en su reciente y cuidadoso estudio sobre la Suprema Corte de Justicia con motivo de su sesquicentenario celebrado precisamente en el año de $1975^{133}$, en el sentido de que deben otorgarsele facultades discrecionales a dicho Alto Tribunal, que actualmente sólo se confieren en forma muy limitada en el juicio de amparo en materia administrativa y en la revisión fiscal, en forma similar a lo que ocurre con la Corte Federal de los Estados Unidos con el "writ of certiorari" 134, con el objeto de que pueda elegir los asuntos que considere de mayor importancia desde el punto de vista jurídico y constitucional.

En efecto, si bien la Suprema Corte de Justicia ha efectuado una labor muy importante respecto a la interpretación del ordenamiento jurídico mexicano, tanto en la esfera federal como local, sin embargo ha estado tan abrumada por su función de tribunal federal de casación - muy importante por otro lado- que no ha podido, salvo casos excepcionales, realizar su atribución todavía de mayor trascendencia de "guardián de la Constitución", en forma siquiera aproximada a la que ha realizado la propia Corte Suprema Federal de los Estados Unidos ${ }^{\mathbf{1 3 5}}$.

2) Por lo que se refiere a los tribunales del Distrito Federal, las reformas de 1971 y las procesales de 1973 no han modificado su situación tradicional, ni han podido superar el rezago que los abruma, el procedimiento escrito, formalista y lento que agobia a los justiciables, ni tampoco se ha establecido una verdadera carrera judicial que pudiese elevar el nivel profesional de los juzgadores.

3) Tal vez en el campo en el cual es posible sostener un desarrollo más firme es el de la justicia administrativa, en cuanto al Tribunal Fiscal creado en 1936 como un órgano de jurisdicción delegada, adquirió en su ley orgánica de 1967 su plena autonomía, y además con motivo de la reforma de 1968 al artículo 104, fracción I, de la Constitución Federal, se estableció en 1971 el Tribunal de los Contencioso Administrativo del Distrito Federal, y además se advierte la tendencia hacia la ampliación de la competencia del propio Tribunal Fiscal Federal para transformarlo en Tribunal Federal de Justicia Administrativa, como lo demuestran los anteproyectos de 1964 y 1973.

4) El Ministerio Público, tanto en el ámbito nacional como del Distrito Federal, así como en las restantes Entidades Federativas, se ha mantenido dentro de los lineamientos trazados por la Constitución vigente, no obstante que se han expedido

131 En el mencionado Segundo Congreso Mexicano de Derecho Procesal efectuado en Zacatecas en agosto de 1966, se aprobó una moción del autor de este trabajo, en el sentido de que el Presidente de la República no pudiese proponer libremente a los miembros de la Suprema Corte, sino que debía sujetarse a ternas propuestas por los miembros de la magistratura federal, los colegios de abogados y las facultades de Derecho, cfr. Héctor Fix-Zamudio, Reformas constitucionales al poder judicial federal, en "Revista de la Facultad de Derecho de México", Núm. 65, enero-marzo de 1967, p. 119.

132 Un organismo similar que se podía denominar Consejo de la Judicatura, lo propusimos y se aprobó en el mismo Segundo Congreso Mexicano de Derecho Procesal, op.ult.cit., p. 121.

133 Un criterio similar se expuso en septiembre de 1965 por el entonces Senador de la República profesor Andrés Serra Rojas, cfr. Héctor Fix-Zamudio, op.ult.cit., pp. 89-90.

134 Cfr. entre muchos otros, André y Suzanne Tunc, El derecho de los Estados Unidos de América, trad. de Javier Elola, México, 1957, p. 70.

$135 \mathrm{Cfr}$. entre otros, Charles Evans Hughes, La Suprema Corte de los Estados Unidos, trad. de Roberto Molina Pasquel y Vicente Herrero, 2a. Ed., México, 1971, y Lêda Boechart Rodrigues, La Suprema Corte y el derecho constitucional norteamericanos, trad. de Justo Pastor Benítez, México, 1965. 
leyes orgánicas recientes, que si bien introducen algunos elementos técnicos, no modifican la dependencia de la institución respecto del organismo ejecutivo ni atenúan su monopolio absoluto del ejercicio de la acción penal.

33. De acuerdo con la situación anterior, las perspectivas del organismo judicial de nuestro país no podemos considerarlas como muy halagüeñas, al menos en un futuro próximo.

En efecto, ya hemos dicho que los estudios sobre este organismo son escasos desde el punto de vista jurídico y todavía no se ha intentado un análisis pluridisciplinario, es decir con la colaboración de otras ciencias sociales, como la sociología, la economía y la ciencia política, siempre bajo el enfoque de nuestra disciplina, que nos permitan hacer un balance más sólido para proponer soluciones realmente de fondo y no como hasta la fecha, simples paliativos, que en ocasiones funcionan por poco tiempo.

Recordemos el ejemplo de la reforma realizada por Franz Klein en los últimos años del siglo pasado, tanto en el campo orgánico como procesal del organismo judicial austríaco, y que ha resistido la prueba del tiempo, pues todavía nos parece moderna.

Claro que desde el ángulo estrictamente jurídico, en diversos congresos procesales se han propuesto remedios técnicos que si bien no podemos considerarlos como definitivos, sí pueden jejorar la situación del organismo judicial en nuestro país.

a) Por lo que respecta al poder judicial federal, reiteramos nuestra convicción de que una vez resuelto, así sea en forma limitada el problema del rezago, debe ahora otorgarse a la Suprema Corte facultades discrecionales en cuanto a su competencia para conocer en amparo o en la vía ordinaria federal, los asuntos que estimara de interés nacional, con el objeto de que pudiera concentrarse en la interpretación de las disposiciones constitucionales, y configurar una verdadera justicia constitucional.

b) En el ámbito local se requieren remedios más enérgicos, y una verdadera restructuración de los tribunales de las Entidades Federativas, a través de la carrera judicial y un control más estricto sobre la conducta de los funcionarios judiciales.

c) Tanto en la esfera nacional como local se requiere que el organismo judicial maneje con libertad su presupuesto, que debe ser suficiente para impartir justicia con prontitud y eficacia; y si es posible, debe contar con un porcentaje del presupuesto nacional y local; creación de escuelas judiciales para los aspirantes a la judicatura, a la cual deben ingresar y ascender sólo por oposición; y el establecimiento de un órgano de designación, promoción y vigilancia, similar al Consejo de la Magistratura o de Justicia que existe en varios países, etc.

d) Al mismo tiempo, debe intentarse la reforma procesal en todas las ramas del enjuiciamiento para actualizar nuestras leyes y códigos objetivos, que en gran parte ya no son aplicables a las nuevas necesidades sociales.

\section{Conclusiones}

34. Las conclusiones de este informe son bastante simples:

Primera. - En los últimos veinticinco años no se observa una evolución dinámica del organismo judicial mexicano, en el ámbito nacional, pero todavía menos en las Entidades Federativas. 
Segunda. - Las reformas constitucionales de 1951 y 1968 tuvieron como propósito esencial terminar con el rezago de los tribunales en la materia de amparo y en particular de la Suprema Corte de Justicia; habiéndose logrado esa finalidad en esta última y parcialmente en los otros tribunales federales.

Tercera. - La Suprema Corte de Justicia ha desarrollado una labor importante en la interpretación del ordenamiento jurídico del país, particularmente como tribunal de casación a través del juicio de amparo contra sentencias judiciales, pero su función como intérprete máximo de la Constitución Federal no posee trascendencia similar a la de la Corte Suprema Federal de los Estados Unidos o los Tribunales Constitucionales de varios países europeos, por dos razones esenciales:

a) El agobio que significa la labor casacionista, sin que pueda elegir discrecionalmente los asuntos que debe conocer, ya que sólo en materia administrativa y a través del juicio de amparo se le han otorgado a partir de 1968, en un ámbito limitado estas facultades discrecionales.

b) Se ha preferido en México para adaptar el texto constitucional a los cambiantes y dinámicas condiciones sociales, políticas y económicas, el camino más sencillo en apariencia, pero que menoscaba el prestigio de la Constitución Federal, de reformar constantemente dicho texto, que ya rebasa las 200 modificaciones a partir de 1917, privando a la Suprema Corte de Justicia de la posibilidad de interpretar evolutivamente las disposiciones fundamentales.

Cuarta. - Todo lo anterior nos indica la necesidad de realizar estudios más profundos y de conjunto, inclusive de carácter pluridisciplinario, para analizar la situación actual del organismo judicial, tanto nacional como local de nuestro país, que nos permita formular las proposiciones fundamentales y no puramente circunstanciales, que nos lleven hacia una verdadera reforma judicial, que desde hace tiempo debe considerarse como indispensable. 


\title{
Constitutionalism and Presidency in Mexico
}

\author{
BY F. WEHNER
}

The Constitution of Querétaro, dated 5th of February of 1917, was intended to be a reformed edition of the Constitution of 1857. In the constitutional reality as it has been developped since 1917, the Constitution is no longer an imitation of the model of USA, but is to be understood as an originally Mexican new Constitution. It contains elements of a socialrevolutionary character, such as a definition of the property on the soil which corresponds Aztec and Spanish traditions with the intention to spoil the privileges of the latifundists; besides new modern basic normes of a social right are stated.

During the years of the twentieths the two Presidents Alvaro Obregón (19201924) and Plutarco Elías Calles (1924-1928) succeeded in fighting down the traditional military Caudillism. Another predominating fact was the founding of an official Party, the "Partido Revolucionario Institucional" - PRI, which stabilized the presidential government acting as an instrument to manage the elections and to dominate the masses of the people.

On this basis the position of the President has reached a highly authoritative character confirming thus the tradition and constitutional reality throughout the Mexican history. Nevertheless the position of the President cannot be compared with absolutism. He is bound to observe the tasks of social progress according to the Constitution and the period of his power is limited to six years without any come-back. This was a dogma of the Revolution of 1910. People acknowledge the presidential power as legitime. Though it is contrary to elements of the written Constitution which still prescribes the division of the legislative, executive and judicial powers. This liberal dogma is no longer in action.

\section{The Judicial System in Mexico}

\section{By Hector Fix-Zamudio}

An analysis of the constitutional origins of the Mexican Judicial System and its evolution during the last 25 years does not show a dynamic evolution, neither on the federal nor on the state level. As far as the constitutional reforms of 1951 and 1968 are concerned, these reforms only intended to relieve the courts - especially the Supreme Court of Justice- from their enormous back-lag in amparo-matters. This has been achieved with regard to the Supreme Court, but only partially with regard to other federal courts. The Supreme Court of Justice has done important work in the field of interpreting the country's judicial system, but nevertheless his role as a final authority in interpreting the constitution has not reached the importance of the U.S. Supreme Court or the courts of some European countries. There are two main reasons for this. The first one is, that even after the reforms mentioned above, the Supreme Court, due to his limited competence for selecting the cases to be judged, is still overburdened in amparo-matters. Secondly, in Mexico, one has always preferred to adapt the text of the constitution to the very dynamicly changing social conditions. This seemed to be the more simple way, but 
thus the prestige of the federal constitution was diminished: The incessant amending of the constitution (more than 200 modifications since 1917) prevented the Supreme Court from interpreting the basic constitutional provisions in an evolutionary way. This point of view underlines the necessity of more, and even of multidisciplinary studies in analysing the country's judicial system both on the national and the local level. Only this way shall lead to fundamental and not only circumstantial propositions striving for a judicial reform, a reform that has been overdue since a long time.

\section{Anthropology and Sociology of Private Law in Mexico}

\section{By Volkmar Gessner}

In view of the recent discussion about the scientific value of "law and development"-studies it appears to be useful to describe the present state of knowledge concerning specific geographical regions and specific areas of law and so to allow a critical review and possibly a reorientation. What we have certainly learned is that approaches which look merely for better legal social engineering in developing countries are subject to serious doubt.

This paper is intended to give access to empirical studies on the relationship between private law (including labour law) and society in Mexico. By describing concrete phenomena of the Mexican law in action (II and III) and introducing subsequently (IV) theoretical concepts for structuring the presented factual knowledge the author argues in favor of a theoretical perception of the function of law in the third world. This position is in sharp contrast to other (legal) scholars participating in the "law and development"-discussion who defend that the only answer to dogmatic orientations of the traditional legal sciences in developing countries is not a social science but a policy approach. The studies referred to in this article are non-normative altogether. Proposals for legal reform are completely absent and even the topics themselves were far away from the mainstreams of political discussions by the time when the research was done in the country. As a result this research had no impact on the making of new laws. On the other hand it is of great importance for legal sociology that Mexico is now one of the few regions in the world where it is possible to analyse the whole range of social structures under the perspective if and to what degree social behavior is influenced by law.

\section{Popular Justice in Zincantan}

\section{By Jane F. Collier}

The town hall court in the Tzotzil Maya community of Zincantan, Chiapas, Mexico functions as a highly successful popular tribunal. It is easily accessible to all citizens, justice is quick and cheap, and it uses procedures intelligible to the uneducated layman. At the same time, the court is highly popular and news of its activities spread rapidly through the community. As a result, it not only 